\title{
Metallic Nanoparticles in Heterogeneous Catalysis
}

\author{
András Sápi ${ }^{1} \cdot$ T. Rajkumar ${ }^{1}$. János Kiss ${ }^{1,2} \cdot$ Ákos Kukovecz $^{1} \cdot$ Zoltán Kónya $^{1,2} \cdot$ Gabor A. Somorjai $^{3}$
}

Received: 14 October 2020 / Accepted: 25 November 2020

(C) The Author(s), under exclusive licence to Springer Science+Business Media, LLC part of Springer Nature 2021

\begin{abstract}
Heterogeneous catalysis is a chemical process achieved at solid-gas or solid-liquid interfaces. Many factors including the particle size, shape and metal-support interfaces can have significant influences on the catalytic properties of metal catalysts. The recent progress in the synthesis techniques and advanced characterization tools allow to understand the catalytic mechanisms at molecular level. In this Review, the size and shape dependent catalytic chemistry of metal nanoparticles and their electronic properties will be discussed. Then the unique catalytic chemistry at the metal-support interfaces will be discussed in details. Furthermore, the challenges of bimetallic nanoparticle catalytic chemistry will be discussed.
\end{abstract}

\section{Graphic Abstract}

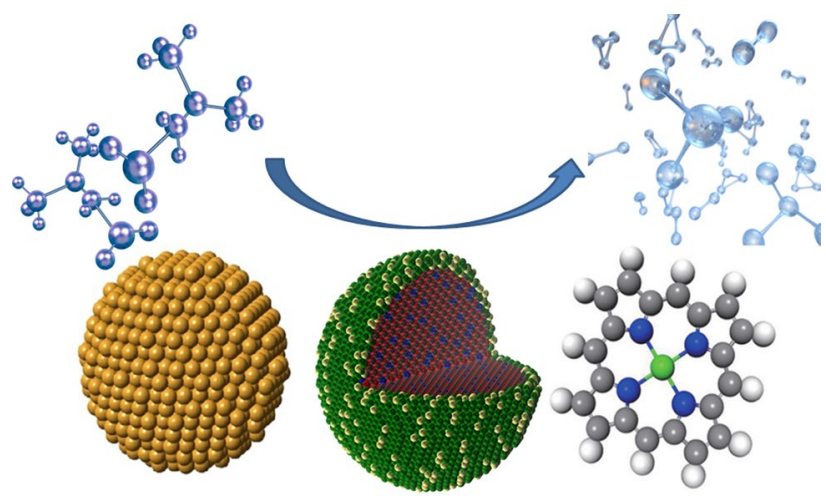

Keywords Metallic nanoparticles $\cdot$ Core-shell nanoparticles $\cdot$ In-situ techniques $\cdot$ Single atom catalysis

András Sápi and T. Rajkumar have contribute equally.

Gabor A. Somorjai

somorjai@berkeley.edu

1 Interdisciplinary Excellence Centre, Department of Applied and Environmental Chemistry, University of Szeged, Rerrich Béla tér 1, Szeged 6720, Hungary

2 MTA-SZTE Reaction Kinetics and Surface Chemistry Research Group, Rerrich Béla tér 1, Szeged 6720, Hungary

3 Department of Chemistry, University of California, Berkeley, CA 94720, USA

\section{Introduction}

Heterogeneous catalysis is vital to produce fuels, fertilizers, and fine chemicals. Heterogeneous catalysts offer many advantages over homogeneous catalysts such as easy catalyst separation and reusability [1-5]. Various methods such as sol-gel process, chemical vapour deposition, chemical reduction method, solution-based synthesis, solvothermal, reverse micelle and co-precipitation methods have been used for the synthesis of metal nanoparticles. Among these methods, the chemical reduction-based polyol and colloidal synthesis methods are more efficient for preparing metal nanoparticles with precise structure. When the size of nanoparticles is decreased to the nanometre scale, the surface to volume ratio increased and hence impart enhanced 
catalytic activity [6]. The electronic and geometric structures of single atoms, nanoclusters, and nanoparticles differ significantly and hence import different catalytic properties [7]. These structure differences are reflected in both thermal and photo-induced processes. The electronic structures of mononuclear metal complex depend on their coordination environment. But for metal clusters and nanoparticles, the scenario become more complicated due to the overlapping of orbital between metal atoms. For instance, frontier orbitals of $2 \mathrm{D} \mathrm{Au}_{\mathrm{n}}$ clusters $(\mathrm{n} \leq 7)$ consist $\mathrm{Au}$ atoms with unsaturated coordination environment and entirely accessible for the interaction with substrates through the overlap of electronic orbitals. But for Au clusters above 8 atoms, the geometric structure of the Au nanocluster will change from $2 \mathrm{D}$ to $3 \mathrm{D}$ and subsequently the coordination number of the surface atoms increases and the orbitals of the atoms inside the clusters/particles overlap less efficiently with substrate molecules compared to that of smaller clusters/particles with entirely accessible orbital structures [8]. Geometric effects were observed when the metal species (single atom or cluster or particle) anchored on supports. When the single atoms anchored on stable supports such as transition metal oxides and zeolites they can be stabilized by chemical bonding and have limited geometric transformation compared to highly reactive supports such as organic polymers under reaction conditions. However, for any metal cluster with specific atomicity, there are several possible geometric configurations which depends on the support, reactant and reaction conditions. NPs with different sizes possess low coordinated corners and edges on the topmost surface layer which were demonstrated as most active sites [9]. Moreover, decrease of particle size changes the electronic structure of metal NPs. The shapes of NPs also have critical effect on catalytic activity due to difference in the exposed facets. High-index faceted nanocrystals are catalytic more active due to their elevated energy surfaces that increase specific activity. Development of in situ characterization methods enabled to identify the electronic and molecular structures of the catalytic active sites and surface intermediates of NPs under operating conditions. Surface sensitive spectroscopic and microscopic techniques such as Near AmbientPressure X-ray Photoelectron Spectroscopy (NAP-XPS), X-ray Absorption Spectroscopy (XAS), different vibration techniques (IR, DRIFTS), high-pressure scanning tunnelling microscopy (STM), transmission electron microscopy, scanning transmission X-ray microscopy have been used for this purpose. The high surface energy of NPs increases their instability and leads to aggregation that cause loss of catalytic activity. Therefore, stabilizing NPs on supports prevents these drawbacks and results in their higher total surface area and consequently enhanced catalytic performance [10]. The activity of the NPs supported catalyst at the metal/ oxide interface depends on bifunctional (both NPs as well as support) effects [11-13] and/or electronic effects [14-16] which contribute to modify the bonding strength. However, it is not possible to distinguish these two effects because they occur simultaneously $[17,18]$.

In this review, we provide an overview of size and shape dependent catalytic chemistry of NPs, electronic and geometric structure of NPs, catalytic chemistry of metal-oxide interface and challenges of bimetallic metal nanoparticle catalytic chemistry. Finally, conclusions will be discussed.

\section{The Size and Shape Dependent Catalytic Chemistry of Metal Nanoparticles}

Metal nanoparticles with different sizes and shapes exhibit different catalytic activity for various heterogeneous reactions [5]. In this section, we discuss the effects of size and shape of nanoparticle catalysts on several catalytic reactions.

\subsection{Synthesis of Metal Nanoparticles}

Various methods such as sol-gel process, chemical vapour deposition, chemical reduction method, solution-based synthesis, hydrothermal/solvothermal, reverse micelle and coprecipitation methods have been used for the synthesis of metal nanoparticles. Among these methods, the chemical reduction-based polyol and colloidal synthesis methods are more efficient for preparing metal nanoparticles with welldefined structure. In polyol method, the polyol such as 1,2diols and ether glycols are used as the liquid organic compound which acts as both as a solvent and reducing agent and sometimes as colloidal stabilizer. The polyol medium offers several other advantages. (i) The high boiling point of the polyols makes them working at high temperature, ensuring that well crystallized NPs are obtained, (ii) it is ability to coordinate metal precursors and NP surface through - $\mathrm{OH}$ groups both facilitates the dissolution of the metal sources and reduces the NP coalescence, (iii) the high viscosity of polyols provides diffusion-controlled regime for the NP growth resulting in controlled structures and morphologies [19]. In colloidal synthesis, the main components necessary for the synthesis of metal nanoparticles are metal precursor, surfactant, solvent, and reducing agent. In a typical synthesis, desired precursors are dissolved into the solvent with the surfactants. The desired metallic nanoparticles were generated at an elevated temperature in the presence of reducing agent. Various metal precursors such as metal chloride, nitrate, sulphate, acetate and acetylacetonate were used. The aggregation and precipitation of metal nanoparticles in solution can be prohibited by using a surfactant. Various surfactants such as polymers and ammonium salts were used. The concentration of surfactant and its ratio to metal precursors determine the particle size and shape of the metal 
NPs. The shape of the metal NPs can be controlled by suitable surfactant, as the binding affinity of a surfactant varies from one crystal facet to another [20].

Two major categories of techniques have been used for the characterization of metal nanoparticles. One is X-ray based techniques such as X-ray diffraction (XRD), Smallangle X-ray scattering (SAXS), Energy-dispersive X-ray spectroscopy (EDXS), X-ray absorption spectroscopy (XAS) and X-ray photoelectron spectroscopy (XPS). The other is microscopy-based techniques such as Transmission electron microscopy (TEM), selected area electron diffraction (SAED), scanning transmission electron microscopy (STEM), High-angle annular dark-field scanning transmission electron microscopy (HAADF-STEM), Electron energy loss spectroscopy (EELS), Scanning electron microscopy (SEM), Atomic force microscopy (AFM) and Scanning Tunneling Microscopy (STM). The other characterization techniques such as Fourier transform infrared spectroscopy (FTIR), Nuclear magnetic resonance (NMR) spectroscopy, Brunauer-Emmett-Teller (BET) surface area analysis, Thermal gravimetric analysis (TGA), UV-Vis spectroscopy, Photoluminescence (PL) spectroscopy, Dynamic light scattering (DLS), Mass spectrometry (MS) and Differential scanning calorimetry (DSC) have also been used for the characterization of metal nanoparticles.

\subsection{Size Effects}

The catalytic oxidation of $\mathrm{CO}$ to $\mathrm{CO}_{2}$ is a well-known heterogeneous reaction [21]. In addition, $\mathrm{CO}$ oxidation is used as probe reaction for oxide surface characterization [22]. Bulk Au surfaces are chemically inert. However, in 1987 Haruta and co-workers showed that nanosized $(<5 \mathrm{~nm}) \mathrm{Au}$ particles deposited on metal oxides can be very effective catalyst for low temperature $\mathrm{CO}$ oxidation [23]. Au particles ranging from 1 to $6 \mathrm{~nm}$ were prepared by Goodman and co-workers. They observed the relationship between the turnover frequency (TOF) of $\mathrm{CO}$ oxidation. The highest TOF was observed for Au with an average particle size of $3 \mathrm{~nm}$ [24]. This is due to the quantum size effects related with small-sized Au catalysts. Au particles with sizes from 2.5 to $6.0 \mathrm{~nm}$ supported on $\mathrm{TiO}_{2}$ were used to study $\mathrm{CO}$ oxidation reaction kinetics. It was observed that the apparent activation energies changed from 1.7 to $5 \mathrm{kcal} \mathrm{mol}^{-1}$ when the $\mathrm{Au}$ particle size was varied from 2.5 to $6.0 \mathrm{~nm}$. The maximum specific rate was observed at $3.5 \mathrm{~nm}$ suggesting that $\mathrm{CO}$ oxidation reaction is structure sensitive [25]. Although $\mathrm{Au}$ particle size has a major effect on CO oxidation activity, other factors such as oxidation state of Au [26-28], presence of low coordinated step and corner Au sites [29], metalnonmetal transitions [24] and metal-support interface [28] are also important.

The Au nanoparticles with the sizes $2-4 \mathrm{~nm}$ exhibit CO oxidation rate more than two orders of magnitude larger than 20-40 nm sized nanoparticles regardless of the reducible $\left(\mathrm{TiO}_{2}, \mathrm{Fe}_{2} \mathrm{O}_{3}\right)$ and irreducible $\left(\mathrm{Al}_{2} \mathrm{O}_{3}, \mathrm{SiO}_{2}\right)$ supports [30] (Fig. 1a). Small Au nanoparticles on various supports adsorb $\mathrm{CO}$ more strongly and therefore support effect observed in $\mathrm{CO}$ oxidation reaction must arise from the interaction of oxygen rather than CO [31]. Sanchez and co-workers have prepared magnesia supported size-selected small monodispersed $\mathrm{Au}_{\mathrm{n}}(\mathrm{n} \leq 20)$ gold clusters and found that $\mathrm{Au}_{8}$ is the smallest catalytically active size for the low temperature $(\mathrm{T}<250 \mathrm{~K}) \mathrm{CO}$ oxidation [32]. Anderson and co-workers reported small activities for cluster sizes even smaller than $\mathrm{Au}_{8}\left(\mathrm{Au}_{\mathrm{n}}\right.$ with $\left.\mathrm{n}=3-7\right)$ on $\mathrm{TiO}_{2}(110)$ single crystal as
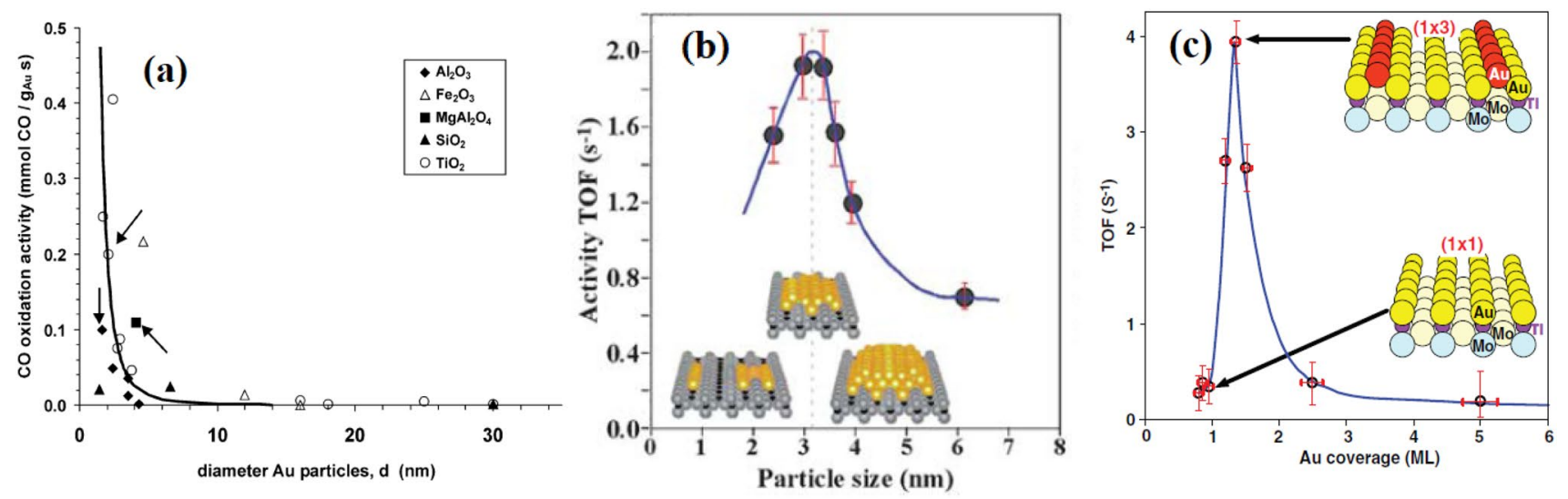

Fig. 1 Measured activities [in $\mathrm{mmol} \mathrm{CO} /\left(\mathrm{g}_{\mathrm{Au}} \mathrm{s}\right)$ ] for $\mathrm{CO}$ oxidation at $273 \mathrm{~K}$ over different Au-based catalysts as a function of the average particle size (d, in $\mathrm{nm})$. Supports are indicated by the symbol shape. Open symbols are used for reducible supports and solid symbols for irreducible supports. The curve shows a $1 / \mathrm{d}^{3}$ guide to the eye, showing that the activity of gold catalysts is approximately proportional with the number of low-coordinated atoms at the corners of the gold particles. b Catalytic activity for $\mathrm{CO}$ oxidation as a function of particle size on the $\mathrm{TiO}_{2}(110)$ at $353 \mathrm{~K}$. c Au coverage on the Mo $(112)-(8 \times 2)-\mathrm{TiO}_{\mathrm{x}}$ at room temperature (reproduced from References $24,30,34)$ 
substrate [33]. Goodman and co-workers investigated $\mathrm{CO}$ oxidation on $\mathrm{Au} / \mathrm{TiO}_{2}$ and observed that $\mathrm{Au}$ with mean particle size of $\sim 3 \mathrm{~nm}$ and a thickness of two atomic layers produced maximum reaction rate (Fig. 1b) [24]. The wellordered monolayer and bilayer films of $\mathrm{Au}$ on $\mathrm{a} \mathrm{TiO}_{\mathrm{x}}$ thin film grown on $\mathrm{Mo}(112)$ were studied by same authors and once again proved that bilayer structure is more active by more than an order of magnitude than monolayer (Fig. 1c) [34]. Apart from Au catalysts, size-dependent $\mathrm{CO}$ oxidation was also noticed over other metal catalysts. For example, An and co-workers prepared $\mathrm{Pt} / \mathrm{Fe}_{2} \mathrm{O}_{3}$ catalysts with Pt particle sizes of $1.1,1.9$ and $2.7 \mathrm{~nm}$ and studied $\mathrm{CO}$ oxidation reaction. The size of the Pt determined the Pt chemical states as well as the strength of metal-support interaction. The relevant metal-support interaction promotes the formation of contiguous $\mathrm{Pt}$ and $\mathrm{Fe}$ sites which is crucial for the activation of $\mathrm{CO}$ and $\mathrm{O}_{2}$ respectively [35].

Somorjai and co-workers reported that the TOF for $\mathrm{CO}$ oxidation was enhanced by a factor of 5 as the Rh particle size decreased from 11 to $2 \mathrm{~nm}$ and the apparent activation energy decreased from 27.9 to $19.0 \mathrm{kcal} \mathrm{mol}^{-1}$ (Fig. 2). The small-sized Rh particles tended to be oxidized more easily than the large ones as revealed by in situ ambient pressure X-ray photoelectron spectroscopy (APXPS) measurements. Moreover, the changes in bonding geometries of $\mathrm{CO}$ and $\mathrm{O}_{2}$ were observed due to the presence of oxide phase and this leads to decrease of activation energy [36].

However, $\mathrm{CO}$ oxidation activity for $\mathrm{Ru}$ with particle size $6 \mathrm{~nm}$ is eightfold higher than $2 \mathrm{~nm}$ particles. It was observed that during the reaction, the metallic Ru transformed into a $\mathrm{Ru} @ \mathrm{RuO}_{2}$ core-shell structure. The lower catalytic activity is due to the conversion of smaller Ru particles into thicker inactive $\mathrm{RuO}_{2}$ shell [37].
Fischer-Tropsch synthesis (FTS) is a catalytic process that converts synthesis gas $\left(\mathrm{CO} / \mathrm{H}_{2}\right)$ obtained from natural gas, coal and biomass into hydrocarbon fuels and chemicals [38-45].

Jong et al. studied the size effects of cobalt nanoparticles on Fischer-Tropsch (FT) synthesis. It was observed that the catalyst activity increased when the particle size of Co increases from 2.6 to $6 \mathrm{~nm}$. The activity decreased quickly when the particle size was higher than $6 \mathrm{~nm}$ (Fig. 3). $\mathrm{C}^{5+}$ selectivity decreased from 85 to $51 \mathrm{wt} \%$ when the cobalt particle size was decreased from 16 to $2.6 \mathrm{~nm}$ [45]. $\gamma-\mathrm{Al}_{2} \mathrm{O}_{3}$ and $\alpha-\mathrm{Al}_{2} \mathrm{O}_{3}$ supported cobalt with particle sizes 2 to $18 \mathrm{~nm}$ were reported. $\mathrm{C}^{5+}$ selectivity exhibited a volcano type curve against Co particle size with particles of 7-8 nm exhibiting the highest $\mathrm{C}^{5+}$ selectivity [46]. $\delta-\mathrm{Al}_{2} \mathrm{O}_{3}$ supported iron oxide with differing particle sizes $(2-12 \mathrm{~nm})$ was studied for FT synthesis. It was observed that the TOF at $300{ }^{\circ} \mathrm{C}$ was increased from 0.02 to $0.16 \mathrm{~s}^{-1}$ when the particle size

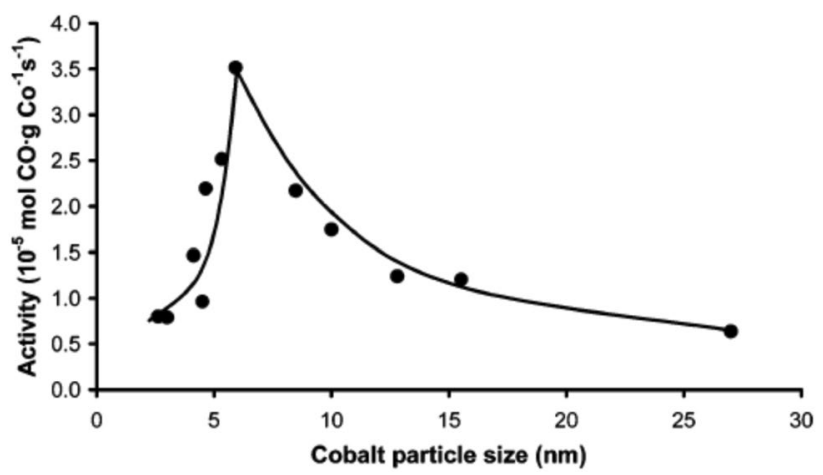

Fig. 3 The activity of cobalt particles with different sizes (reproduced from Reference 45)
Fig. 2 TOFs and activation energies for $\mathrm{CO}$ oxidation as a function of rhodium diameter (reproduced from Reference 36)

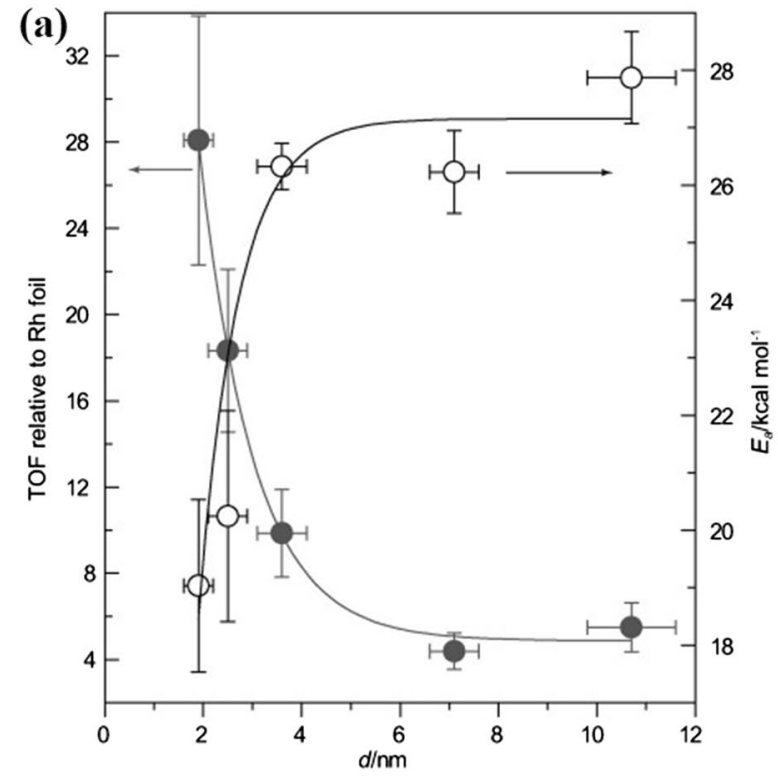

(b)

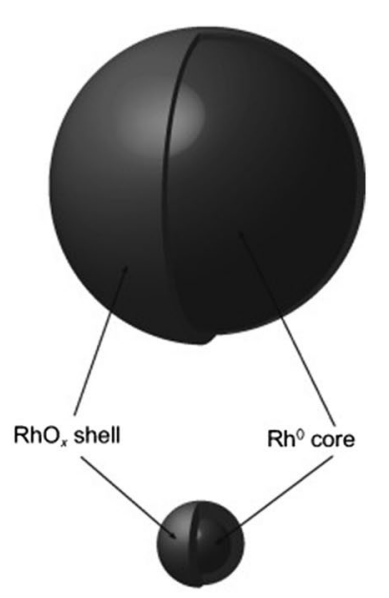




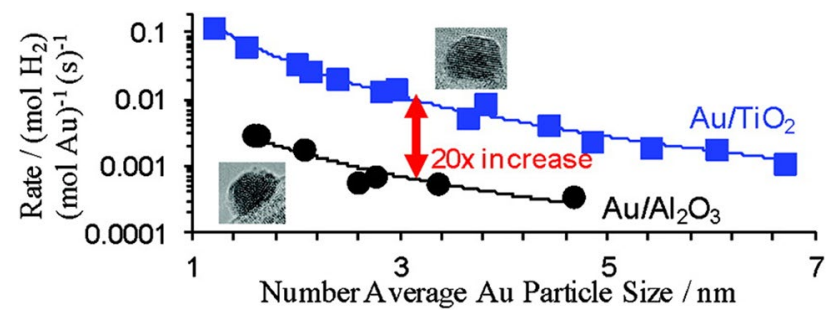

Fig. 4 Rate per total mole for $\mathrm{Au} / \mathrm{Al}_{2} \mathrm{O}_{3}$ and $\mathrm{Au} / \mathrm{TiO}_{2}$ catalysts versus Au particle size (reproduced from Reference 56)

increased from 2.4 to $6.2 \mathrm{~nm}$ and then reached plateau up to a particle size of $11.5 \mathrm{~nm}$ [47]. The effect of the iron carbide particle size has been studied for FT synthesis. The TOF increased 6-eightfold when the average iron carbide size decreased from 7 to $2 \mathrm{~nm}$ [44]. Ru is known as the most active metal than $\mathrm{Fe}$ and Co catalysts for FT synthesis. Carballo and co-workers demonstrated that the TOF of CO consumption increases with the Ru particle sizes reaching constant value for larger than $10 \mathrm{~nm}$. The lower activity for $\mathrm{Ru}$ nanoparticles below $10 \mathrm{~nm}$ is due to the stronger $\mathrm{CO}$ adsorption and subsequent partial blocking of active sites [48].

Water-gas shift reaction is an important industrial reaction for the production of high-purity hydrogen for fuel cells and various industrial applications [49-54]. Mesoporous $\mathrm{CeO}_{2}$ supported $\mathrm{Au}$ nanoparticles $\left(\mathrm{Au} / \mathrm{CeO}_{2}-\mathrm{M}\right)$ and nanorod $\mathrm{CeO}_{2}$ supported $\mathrm{Au}$ nanoparticles $\left(\mathrm{Au} / \mathrm{CeO}_{2}-\mathrm{R}\right)$ were studied for WGS reaction. The smaller particle size of gold in $\mathrm{Au} / \mathrm{CeO}_{2}-\mathrm{M}$ than in $\mathrm{Au} / \mathrm{CeO}_{2}-\mathrm{R}$ indicates that the mesoporous $\mathrm{CeO}_{2}$ was able to disperse nano-sized gold particles than nanorod $\mathrm{CeO}_{2}$ and leading to enhanced activity for the WGS reaction [55]. The size effects of Au nanoparticles for $\mathrm{Au} / \mathrm{Al}_{2} \mathrm{O}_{3}$ and $\mathrm{Au} / \mathrm{TiO}_{2}$ catalysts were also studied for the WGS reaction. The $\mathrm{H}_{2}$ production rate normalized by the number average Au particle size indicated that the activity constantly decreased with the increase of Au particle size (Fig. 4) [56].

\subsection{Shape Effects}

It is well-known that the catalytic properties of nanocrystals have a significant effect on their shape which determines surface atomic arrangement and coordination [57, 58]. Metal nanocrystals with high-index facets display higher catalytic activities due to the presence of high-density atomic steps, edges and kinks which are usually considered active sites for chemical bond breaking. Somorjai and co-workers were studied crystal facet dependent iron catalysed ammonia synthesis using (111), (100) and (110) planes. The Fe (111) plane displayed the highest activity and the activity ratio were 418:25:1 for the (111), (100) and (110) planes [59].
Somorjai et al. also studied benzene hydrogenation catalyzed by cubic particles consist of only Pt (100) and cuboctahedra consist of both Pt (100) and Pt (111) surfaces. It was observed that cyclohexane was the only product formed over cubic Pt (100), while cyclohexane and cyclohexene were formed over cuboctahedral Pt (100) and Pt (111) surfaces [60]. The Pt tetrahexahedral (THH) shaped nanocrystal enclosed by 24 high-index facets such as (730), (210), and (520) with large density of atomic steps and dangling bonds exhibit up to $400 \%$ higher catalytic activity than equivalent $\mathrm{Pt}$ surface areas for electro-oxidation of small organic fuels such as formic acid and ethanol [58]. Zhang et al. studied triiodide reduction over (100), (111) and (411) facets of Pt nanocrystals using density functional theory. It was shown that the activity follows the order, $\mathrm{Pt}(111)>\mathrm{Pt}(411)>\mathrm{Pt}$ (100). Further, Pt nanocrystals with the above facets were synthesized and used as counter electrode materials for dye-sensitized solar cells (DSCs) and observed highest photovoltaic conversion efficiency on Pt (111) surface in DSCs confirms the theoretical study [61]. Perez et al. studied the hydrogen evolution reaction on the low index planes of single crystal Au electrodes and observed that the catalytic activity increases with atomic density of the surface and follow the sequence $\mathrm{Au}$ (111) $>\mathrm{Au}(100)>\mathrm{Au}$ (110) [62]. Chiu et al. prepared cubic, octahedral, and rhombic dodecahedral gold nanocrystals by a seed-mediated growth method. It was observed that the catalytic activity for the reduction of p-nitroaniline to p-phenylenediamine follows the order $(110)>(100)>(111)$ [63]. Zhang et al. prepared cubic and octahedral Pd nanocrystals. It was observed that the (100) facet enclosed Pd nanocubes showed enhanced catalytic activity than Pd octahedrons with (111) facets for electrochemical oxidation of formic acid [64]. Shen et al. prepared spherical and sheetlike $\mathrm{Ag} / \mathrm{AgCl}$ nanostructures [65]. The obtained sheetlike $\mathrm{Ag} / \mathrm{AgCl}$ displayed enhanced catalytic performances for the photodegradation of methyl orange compared to spherical $\mathrm{Ag} / \mathrm{AgCl}$ nanostructures due to the presence of (111) enriched facets. However, for the 4-chlorophenol or phenol as substrate, the spherical Ag/ $\mathrm{AgCl}$ nanostructures displayed superior catalytic activities compared to sheetlike $\mathrm{Ag} / \mathrm{AgCl}$ nanostructure indicates facet-selective but substrate-sensitive catalytic activities. Yang et al. reported that the anatase $\mathrm{TiO}_{2}$ with exposed (001) facets displayed higher photocatalytic activity than the one with exposed (101) facets due to the higher surface energy of the (001) facets than that of the (101) facets [57, 66]. Bi et al. reported the synthesis of $\mathrm{Ag}_{3} \mathrm{PO}_{4}$ rhombic dodecahedrons with exposed (110) facets and cubes exposed by (100) facets. The photocatalytic activity of rhombic dodecahedrons exhibits much higher activities than cubes for the degradation of organic contaminants due to the higher surface energy of (110) facets $\left(1.31 \mathrm{~J} \mathrm{~m}^{-2}\right)$ than of (100) facets $\left(1.12 \mathrm{~J} \mathrm{~m}^{-2}\right)$ [67]. $\mathrm{Co}_{3} \mathrm{O}_{4}$ nanosheets with (112) plane, nanobelts with 
(011) plane and nanocubes with (001) plane was prepared by hydrothermal method. The catalytic performance for methane combustion follows the order $(112)>(011)>>(001)$ [68]. A facet dependent $\mathrm{CO}$ oxidation has been reported over Pd nanocrystal. It was observed that the octahedral and spherical nanoparticles that mostly exposed the Pd (111) crystal facets displayed considerably superior catalytic activity than the palladium cubes that had the Pd (100) crystal facets owing to the much stronger adsorption strength of $\mathrm{CO}$ molecules on Pd (111) planes than on Pd (100) planes [69]. The toxic $\mathrm{Cr}(\mathrm{VI})$ reduction to nontoxic $\mathrm{Cr}(\mathrm{III})$ was investigated over $\mathrm{Cu}_{2} \mathrm{O}(100)$ and (111) facets. It was observed that (100) facets displayed higher activity than on (111) facets [70]. Pal and co-workers studied nitroarene reduction using $\mathrm{CuO}-\mathrm{MnO}_{2}$ composite with (111) and (100) facets. It was shown that the (111) facet of the composite was more active than that of the (100) facet [71]. Tetrahexahedral (THH) Au nanocrystals with 24 high-index (037) facets have been synthesized by seed-mediated growth. Electrochemical studies reveal that high-index (037) facets are more active than octahedral Au nanocrystals with low-index (111) facets [72]. Trapezohedron shaped (TS) $\mathrm{In}_{2} \mathrm{O}_{3}$ particles with exposed high-index (211) facets were successfully synthesized by simple wet chemistry route. It was observed that the gas sensing activity of TS $\operatorname{In}_{2} \mathrm{O}_{3}$ particles with high-index (211) facets is higher than that of octahedron-shaped $\mathrm{In}_{2} \mathrm{O}_{3}$ particles with exposed low-index (111) facets [73]. Photocatalytic degradation of methylene blue was carried out on two different hematite nanoplates. It was observed that hexagonal nanoplates with (110), (102) and (104) facets exhibit enhanced photocatalytic activity than hematite cylindrical nanoplates that expose only (110) and (102) facets [74]. It was found that mostly exposed planes of (001) and (110) in the $\mathrm{CeO}_{2}$ nanorods are more reactive for $\mathrm{CO}$ oxidation than the (111) plane in the irregular $\mathrm{CeO}_{2}$ nanoparticles [75]. Zhang et al. reported the preparation of Pt nanocrystals by solvothermal method. It was found that the high-index (211) and (411) surfaces displayed much better catalytic activity in the electro oxidation of ethanol than Pt nanocubes with low-index (100) surfaces and the catalytic performances of Pt nanocrystal facets decreased in the sequence (411) $>(211)>(100)$ [76]. The facet dependent electrocatalytic activity of $\mathrm{MnO}$ nanocrystals for oxygen evolution reaction (OER) and oxygen reduction reaction (ORR) were studied. The $\mathrm{MnO}$ exposed (100) facets with higher adsorption energy of $\mathrm{O}$ species were found to be responsible for higher electrocatalytic activity [77]. Chanda et al. studied the catalytic activity for the synthesis of 1,2,3-Triazoles on $\mathrm{Cu}_{2} \mathrm{O}$ nanocrystals. It was observed that rhombic dodecahedral $\mathrm{Cu}_{2} \mathrm{O}$ nanocrystals exposed by (110) facets were much more catalytically active than $\mathrm{Cu}_{2} \mathrm{O}$ octahedra exposing (111) facets. However, $\mathrm{Cu}_{2} \mathrm{O}$ nanocubes showed lower catalytic activity [78].

\section{The Metal Nanoparticles Ionisation at Sub-Nanometer Size}

The importance of the size and shape of supported metal nanoparticles correlated with their electronic structure on different oxides were studied by thermal and photoinduced catalytic reactions. The chemical potential versus particle size across the full size range between single isolated atom and bulk like limits is reported [79]. Very recently, metals for heterogeneous catalysis were surveyed from single atoms to nanoclusters and nanoparticles [7]. It is considered that small clusters $(<1-2 \mathrm{~nm})$ lose their bulk-like electronic
Fig. 5 Geometric electronic structures of single atom, clusters, and nanoparticles. (Reproduced from Reference [7])

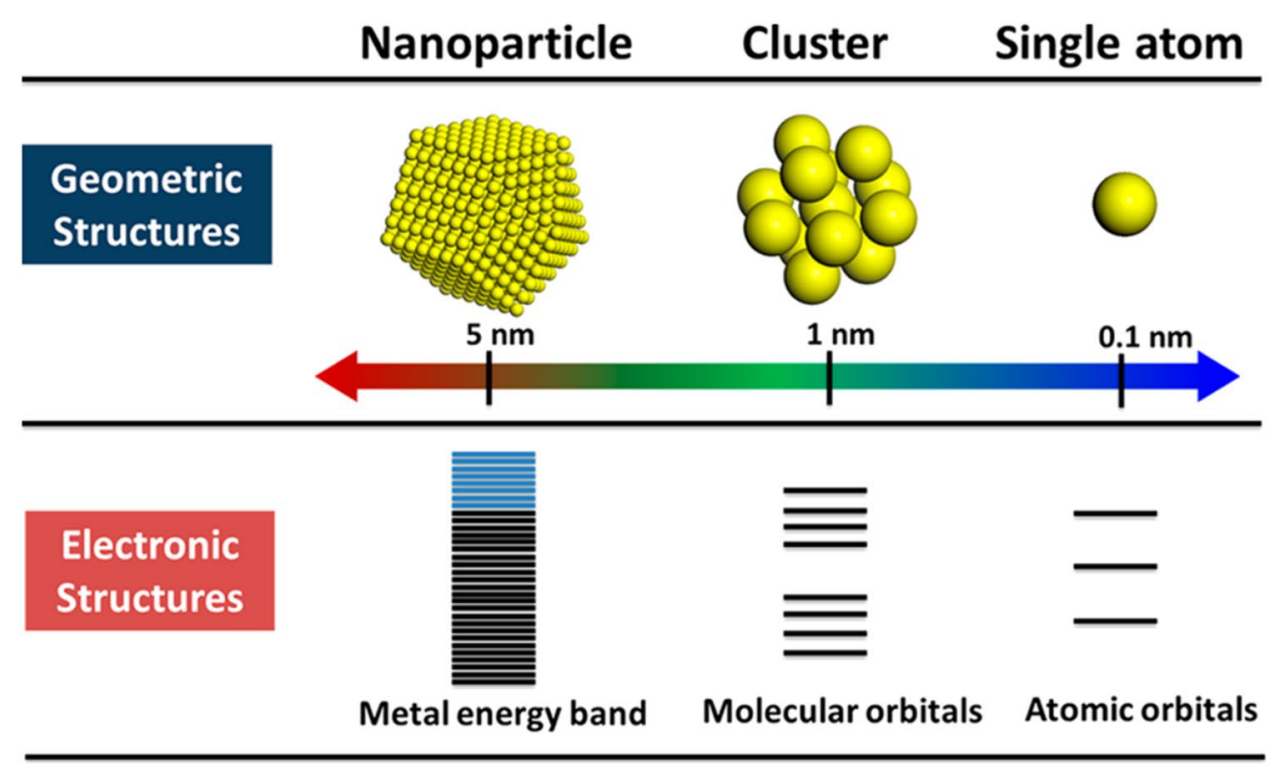


properties (e.g. no Fermi level). For example, they no longer support the plasmonic excitation characteristic of relatively large metal nanocrystals $(3-50 \mathrm{~nm})$. One could already infer that the electronic properties of metal particles should strongly change when going below sub-nanometer $(\sim 1 \mathrm{~nm})$ sizes (Fig. 5). It could be expected that metal clusters in subnanosize would interact differently with reactants, showing distinct reactivity compared to large nanoparticles [80]. The size-dependent electronic structure is more significant when the metal nanoclusters consist of less than 40 atoms [81].

With the advent of modern techniques, it is possible to visualize not only the small clusters but also single atoms and sub-nanometric metal clusters formed by a few atoms, by means of the aberration-corrected electron microscopy [82]. Moreover, new synthesis method such as mass selected technique allow one to prepare metal moieties with a very narrow size distribution [83]. Supported and size-controlled Au clusters can be also prepared with the thiol-ligated solution-based method [84, 85].

Although considerable progress has been made in nanocatalysis, it remains great challenge to fully understand the nature of active sites in the nanoscale. Recently $\mathrm{Li}$ et al. [86] proposed a perspective on the active sites of heterogeneous catalysis from the aspect of electronic structure and geometric structure of nanoclusters and considered how these clusters function in catalysis. It is difficult to distinguish whether the changes of the activities resulted from the electronic effect or structural effects. Scott Anderson [83] applied the mass selected technique to prepare $\mathrm{Pd}\left(\mathrm{Pd}_{\mathrm{n}}\right.$, $\mathrm{n}=1,2,4,7,10,16,20,25)$ supported on $\mathrm{TiO}_{2}(110)$ and study their $\mathrm{CO}$ oxidation activities. The result was that the cluster size did not vary monotonically with $\mathrm{CO}$ oxidation rate, while the Pd 3d binding energy variation correlated with that change. The author thus attributed the $\mathrm{CO}$ oxidation activities of $\mathrm{Pd}_{\mathrm{n}} / \mathrm{TiO}_{2}$ to the electronic structures. The relationship between the electronic structure and adsorption properties are described more clearly by studies of density of states [87].

It is difficult to distinguish electronic and geometric effects as these two effects occur concurrently. Some researchers studied the metal clusters in the gas phase to avoid the complications arising from metal- support interaction $[34,88]$.

The experimental vibrational spectrum and the DFT calculations revealed that the $\mathrm{Au}_{7}$ cluster would change its geometries for the different charge states, so that $\mathrm{Au}_{7}^{-}, \mathrm{Au}_{7}$, and $\mathrm{Au}_{7}{ }^{+}$could be assigned (Fig. 6a). When the tetrahedral $\mathrm{Au}_{20}$ cluster lost its corner atom, it could be reflected in the spectrum of $\mathrm{Au}_{19}$ because of the reduction of symmetry (Fig. 6b). The clusters tend to lessen the average coordination and transform to a more open structure when the electron density increases. As we all know, the electronic structure of the nanoparticle is the transition between the
A
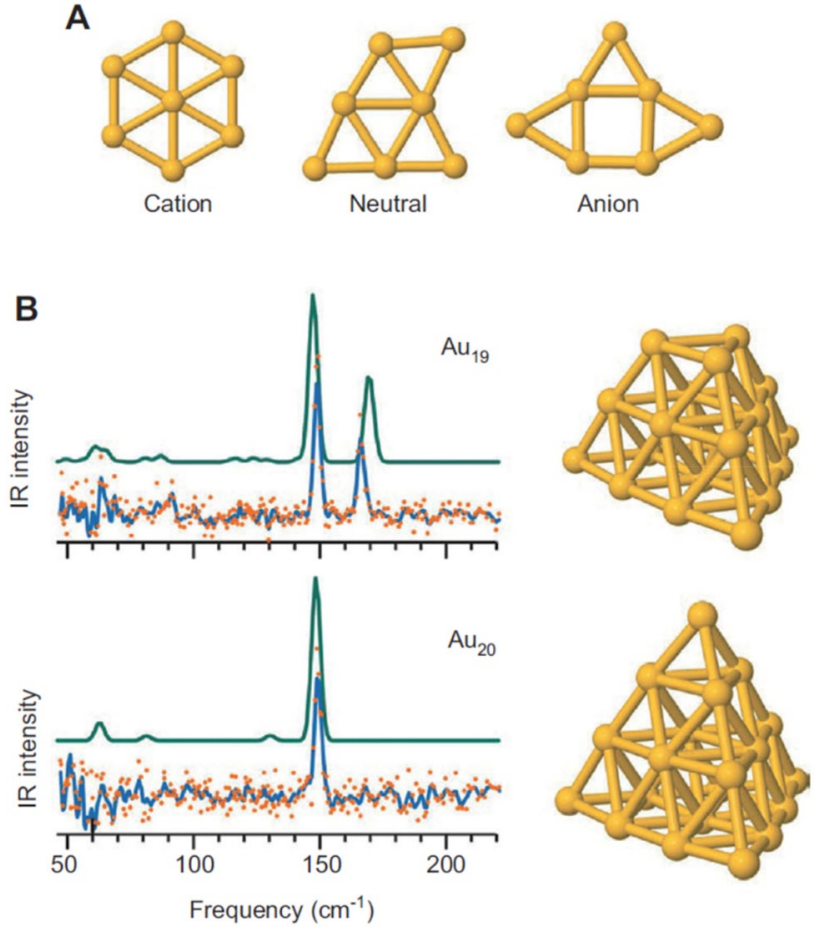

Fig. 6 a The structures of gold clusters containing seven Au atoms vary for the different charge states. $\mathbf{b}$ Comparison of the experimental and calculated IR spectra for $\mathrm{Au}_{19}$ and $\mathrm{Au}_{20}$. (Reproduce from [88]) Reference

split-level of the molecule and continuous energy band of the solid. Therefore, it is difficult to discuss solely the relation of the electronic structure of individual active sites with its chemical properties [86].

The size of nanoparticles also plays an important role in photo and external energy mediated surface chemistry. Elucidating molecular energy transfer processes at metal surfaces is challenging because the energy dissipates within femtoseconds or picoseconds by non-adiabatic electron excitation (i.e., e-h pairs). Generally, depositing noble metals onto a semiconductor surface can appreciably suppress the rate of exciton recombination as the clusters serve as electron sinks [89]. When the photogenerated electrons are produced in the semiconductor, they will probably be transferred to the metal particles through a Schottky barrier. The charge transfer rates between oxide nanoparticles and $\mathrm{Au}$ clusters may depend on cluster size. It is well-demonstrated in the case of $\mathrm{ZnO} / \mathrm{Au}_{\mathrm{n}}$ system displayed in Fig. 7 [90].

Ultrafast spectroscopic measurements showed that when the Au particle size increases from ca. $<2-3 \mathrm{~nm}\left(\mathrm{Au}_{25}\right)$ to ca. $<3.5 \mathrm{~nm}\left(\mathrm{Au}_{807}\right)$, the charge-transfer rate also increases, leading to higher photocatalytic activity in the case of thionine degradation. Such "molecular-like" clusters can be stabilized on several oxides. Besides small clusters, single atoms or ions can be stabilized by oxides. In this study, we 

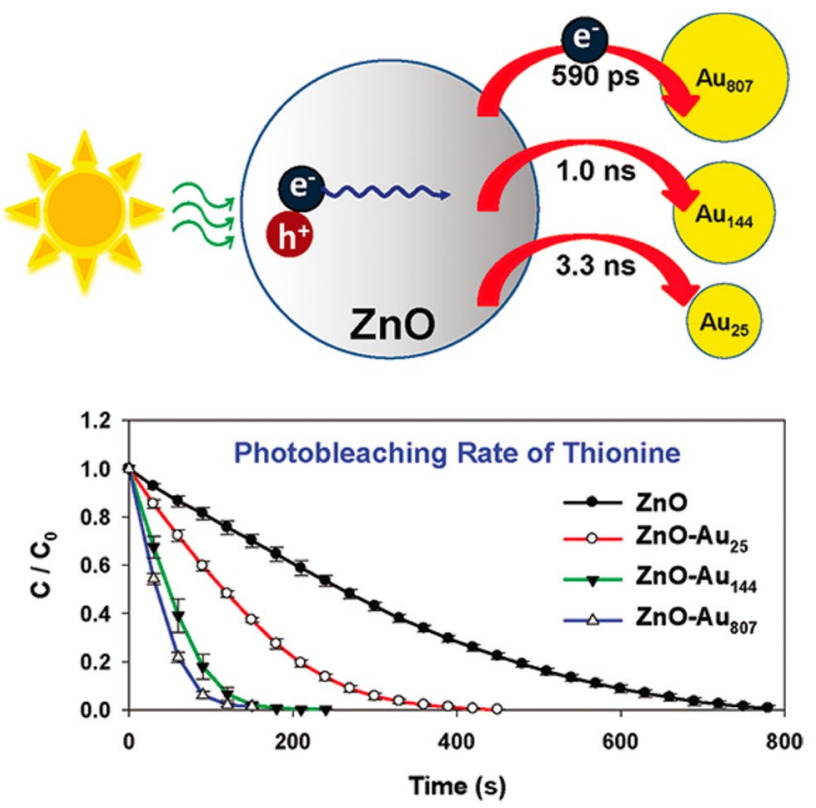

Fig. 7 Schematic illustration of charge transfer between $\mathrm{ZnO}$ nanoparticles and Au particles with different size. The kinetic curve of photocatalytic degradation of thionine (a model dye molecule). (Reprinted with permission from [90]) Reference

focus mostly on "molecular-like" gold clusters $\left(\mathrm{Au}_{\mathrm{n}} ; \mathrm{n} \leq 25\right)$ and single gold atoms or gold ions $\left(\mathrm{Au}^{\mathrm{n}+} ; \mathrm{n} \geq 1\right)$, which could contribute to developing further a progressive direction in heterogeneous catalysis.

Gold nanoclusters (AuNCs) formed on oxide supports have been found to be catalytically active depending on the number of atoms forming the clusters [91, 92]. The catalytic properties depend on the $\mathrm{Au}-\mathrm{Au}$ distance, the coordination number and the electronic structure of the cluster [93, 94]. Scanning probe techniques were used to determine the electronic and structural properties of supported particles as a function of the number of $\mathrm{Au}$ atoms in the particle on $\mathrm{MgO}$ and other doped oxide materials. It was demonstrated how charge transfer between the support and the particles determines the shape of nanoparticles [95]. The oxidation of $\mathrm{CO}$ was investigated on $\mathrm{Au}_{8}$ clusters on $\mathrm{MgO}[28,32]$. It was found that gold octamers bound to oxygen vacancies (F centers) of the magnesia surface can oxidize $\mathrm{CO}$ into $\mathrm{CO}_{2}$ at as low as $140 \mathrm{~K}$. The same clusters bound to oxygen vacancyfree $\mathrm{MgO}$ are catalytically inactive in $\mathrm{CO}$ combustion.

Thiol-stabilized gold nanoclusters have attracted significant research interest not only in catalysis [28, 96-99], but also in biomedicine [100] and chemical sensors [101]. X-ray crystallographic analysis revealed that the $\mathrm{Au}_{25}$ cluster is based on a centred icosahedral $\mathrm{Au}_{13}$ core capped by an exterior shell composed of the remaining twelve $\mathrm{Au}$ atoms, and the whole cluster is encapsulated by eighteen thiolate ligands $\left(\mathrm{SR}=-\mathrm{SCH}_{2} \mathrm{CH}_{2} \mathrm{Ph}\right)[84,102]$. Because of strong quantum size effects, the $\mathrm{Au}_{25}$ cluster shows multiple molecular-like transitions in its optical absorption spectrum; well-defined bands are observed in the UV-Vis spectrum at 1.8, 2.75, and $3.1 \mathrm{eV}$ [84]. For thiol-stabilized $\mathrm{Au}_{38}$ clusters, different bands were observed at 1.64 and $2.0 \mathrm{eV}$ [99].

Recently $\mathrm{Au}_{25}(\mathrm{SR})_{18}\left(\mathrm{SR}=-\mathrm{SCH}_{2} \mathrm{CH}_{2} \mathrm{Ph}\right)$ has been successfully deposited on $\mathrm{CeO}_{2}$ rods [85], as demonstrated in Fig. 8. A HAADF-STEM image of the as-synthesized $\mathrm{Au}_{25}(\mathrm{SR})_{18} / \mathrm{CeO}_{2}$ rod catalysts with the UV-Vis spectrum and MS pattern of the as-synthesized $\mathrm{Au}_{25}(\mathrm{SR})_{18}$ nanoclusters are displayed. This gold cluster on ceria system was explored in $\mathrm{CO}$ oxidation as a probe reaction. Kinetic studies, in situ IR and X-ray absorption spectroscopy, and
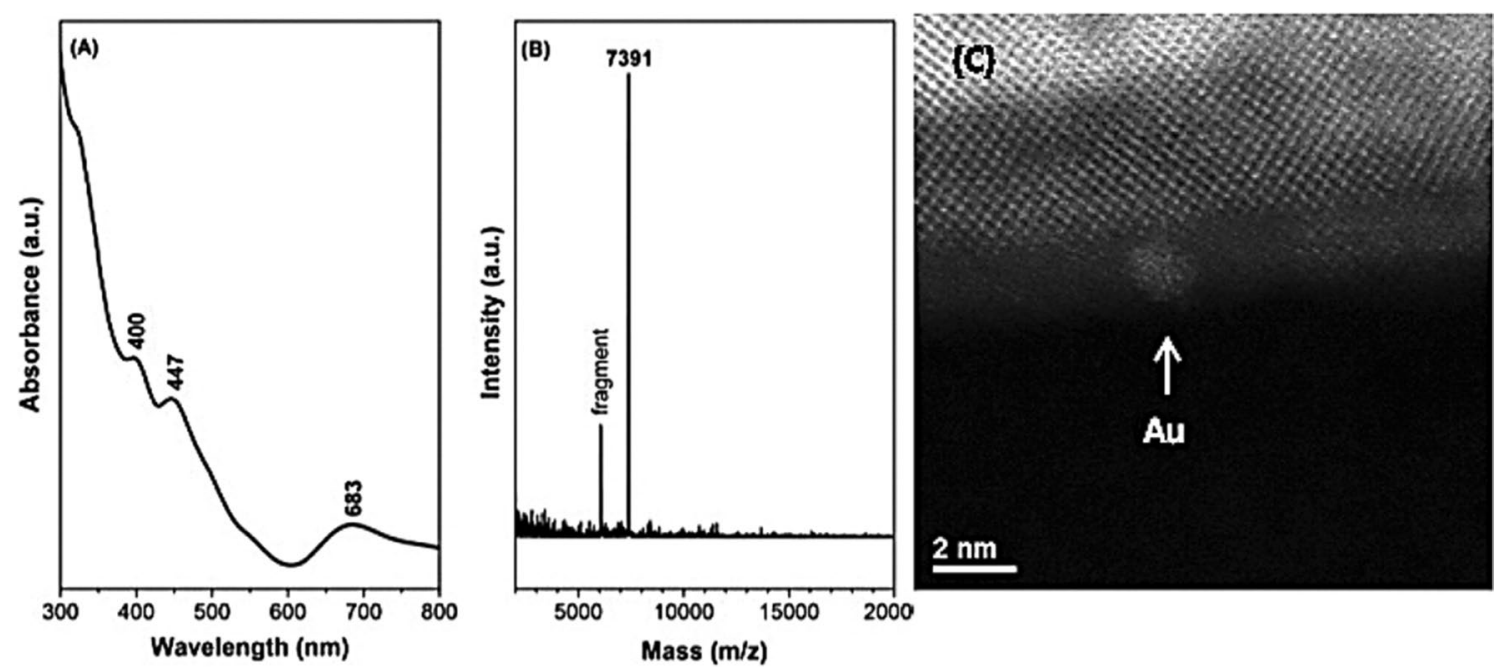

Fig. 8 a UV-Vis spectrum and $\mathbf{b}$ MS pattern of the as-synthesized $\mathrm{Au}_{25}(\mathrm{SR})_{18}$ nanoclusters, $\mathbf{c}$ HAADF-STEM image of the as-synthesized $\mathrm{Au}_{25}(\mathrm{SR})_{18} / \mathrm{CeO}_{2}$ rod catalysts. The scale bar represents $2 \mathrm{~nm}$. (Adapted with permission from [85]) Reference 
density functional theory (DFT) were employed to characterize the reaction. The intact $\mathrm{Au}_{25}(\mathrm{SR})_{18}$ on the $\mathrm{CeO}_{2}$ rod was unable to adsorb $\mathrm{CO}$. $\mathrm{CO}$ activation occurs after thiolate ligands are removed and subsequently $\mathrm{CO}$ oxidation occurs below $423 \mathrm{~K}$. Cationic Au sites (charged between 0 and +1 ) are found to play a major role in low-temperature $\mathrm{CO}$ oxidation. The particle size of $\mathrm{Au}(1-1.5 \mathrm{~nm})$ was the same in the unsupported and the $\mathrm{CeO}_{2}$ supported case.

Small, even sub-nanosized clusters can be prepared on non-oxide type supports as well. The graphene structure is a good candidate for size selective metal deposition [103, 104]. Very small Au clusters can also be prepared on hexagonal boron nitride $[105,106]$. It was demonstrated that for these small clusters $\left[\mathrm{Au}_{\mathrm{n}},(\mathrm{n}=2-4)\right.$ on $\mathrm{h}-\mathrm{BN} / \mathrm{Rh}$ (111) nanomesh] a linear geometry is the most stable. All atoms in these clusters are negatively charged and might be catalytically active $[107,108]$. Porphyrin-related macrocycles are also able to stabilize different atoms or ions on the surface. Their surface can be modified with co-deposited metal atoms, substrate metal atoms and oxide lattice ions. Their catalytic application is well-documented in a recent review [109].

Recently single atom catalysts (SACs) have been proposed as a highly active catalytic system. Single atom catalysts can have positive benefits of both homogeneous and heterogeneous catalytic systems [110]. They are both highly active and stable where all the used metal atoms are active. Due to the evolvement of surface analysing techniques, the existence of the supported single atoms can be proved. EXAFS, HAADF-STEM, FTIR and STM can be powerful tool for characterization of SACs. In CO oxidation reaction $\mathrm{Pt}_{1} / \mathrm{FeO}_{\mathrm{x}}$ is $\sim 3$ times more active than the supported $\mathrm{Pt}$ nanoparticles [111]. $\mathrm{Au}$ atoms on $\mathrm{CeO}_{2}$ nanorods [112] are highly active for methanol steam reforming. The hydrocarbon conversion towards hydrogen is the heart of the hydrogen economy. Single atom platinum supported on $\mathrm{CeO}_{2}$ can convert hydrogen from methanol [113]. These single site Pt catalysts also convert cyclohexane to benzene and rehydrogenate benzene to cyclohexane or rehydrogenate methyl cyclopentane to toluene.

Maximum dispersion of the active components in $\mathrm{Me} /$ $\mathrm{MeO}$ system can be achieved in so-called "solid solution" for example in the case of ceria support, $\mathrm{Ce}_{1-\mathrm{x}} \mathrm{Me}_{\mathrm{x}} \mathrm{O}_{2-\delta}$ with active component being ionically dispersed within $\mathrm{CeO}_{2}$ lattice [114]. Thus, $\mathrm{Ce}_{1-x} \mathrm{Rh}_{\mathrm{x}} \mathrm{O}_{2-\delta}$ solid solution with ionically dispersed $\mathrm{Rh}^{3+}$ species is a promising catalysts for reaction of $\mathrm{CO}$ oxidation and NO reduction $[115,116]$. Initial $\mathrm{Rh}$-doped $\mathrm{CeO}_{2}$ catalysts contained $\mathrm{Rh}^{3+}$ species ionically dispersed in $\mathrm{CeO}_{2}$ lattice and showed activity in $\mathrm{CO}+\mathrm{NO}$ reaction already at room temperature. Reduction treatment of $\mathrm{Rh}^{3+}{ }_{-} \mathrm{CeO}_{2}$ catalysts resulted in the formation of $\mathrm{Rh}$ particles of $\sim 1 \mathrm{~nm}$ in size on reduced ceria surface. The catalytic behaviour of initial and reduced samples was comparable, indicating the nature of active sites and their dynamic formation directly under reaction conditions [117].

Titanates with charged skeletons can change and/or adopt ions into their structures resulted in the atomic dispersion of the catalysts in the surface as well as the structure.

Titanates are salts of polytitanic acid that can be synthesized as nanostructures in a great variety concerning crystallinity, morphology, size, metal content and surface chemistry. Recently, the structure and properties of titanate nanotubes (TNTs) were widely characterized by various techniques [118-124]. They are open-ended hollow cylinders measuring up to $200 \mathrm{~nm}$ in length and $15 \mathrm{~nm}$ in outer diameter $[119,120]$.

Positively charged Au atom incorporated in ion-exchange position of titanate nanotubes and the small cluster in $\mathrm{Au}_{25}{ }^{+}$ strongly contribute to the enhanced activity of titanates in the photo-assisted $\mathrm{CH}_{4}$ decomposition [80]. The adsorbed methane may be directly activated by small Au clusters and ions. In previous works [80, 120, 122-124], it was demonstrated that the XP spectra reflect the formation of $\mathrm{Au}^{+}$(gold in ion-exchange position) and small clusters. HRTEM experiments demonstrated gold clusters in small size $(\mathrm{d}=3.1 \pm 0.9 \mathrm{~nm})$. The DR-UV-VIS spectrum of Au/ TNT shows a strong absorption band at $2.31 \mathrm{eV}(534 \mathrm{~nm})$ (Fig. 9). This is the characteristic absorption of the surface
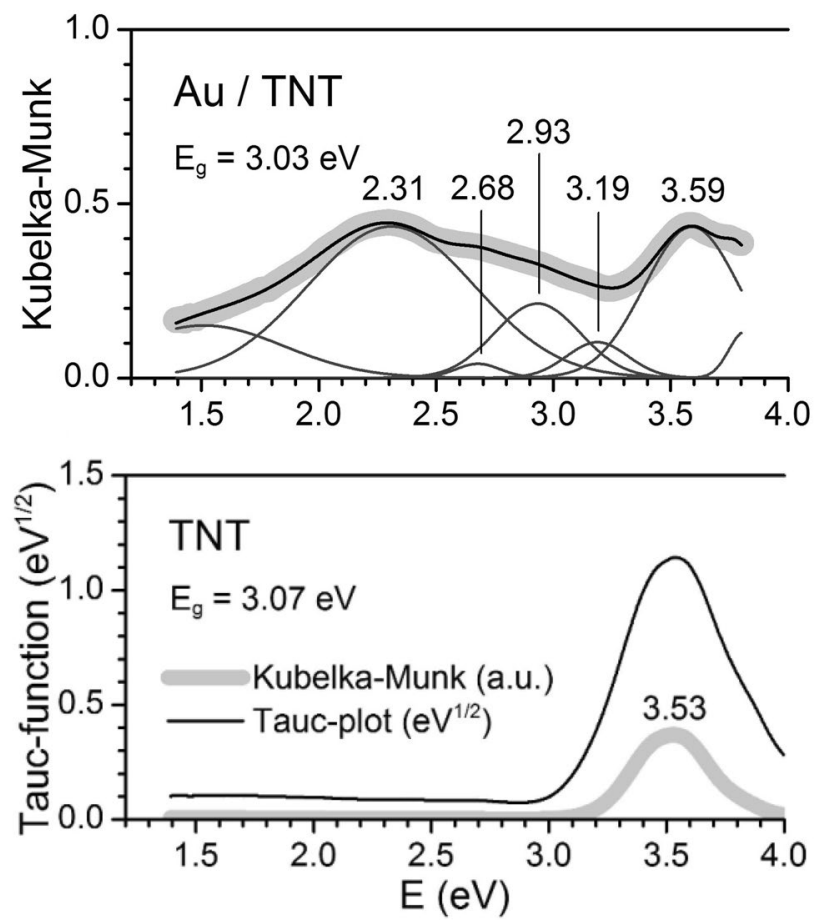

Fig. 9 DR-UV-VIS spectra with the calculated bandgap energies of two different samples. The original spectra are shown by the thick, grey curves. Bandgap energies were calculated from fitted Gaussian functions with Tauc's method in all cases. (Partially reproduced from Reference [123]) 
plasmon of gold nanoparticles $(\mathrm{d}>3 \mathrm{~nm})$ and arises because of the collective modes of oscillation of the free conduction band electrons induced by an interacting electromagnetic field. The spectrum also shows some unresolved peaks, mostly at higher energies. After deconvolution we can identify four absorptions at $1.60 \mathrm{eV}(774 \mathrm{~nm}),(2.68 \mathrm{eV}$ $(426 \mathrm{~nm})), 2.93 \mathrm{eV}(423 \mathrm{~nm})$, and $3.19 \mathrm{eV}(388 \mathrm{~nm})$, due to small clusters (Fig. 9). These absorptions can be attributed to molecular-like $\mathrm{Au}_{25}$ clusters. A similar $\mathrm{Au}_{25}$ cluster was identified on $\mathrm{CeO}_{2}$ rod catalyst [85]. Based on these similarities in the UV-Vis spectra, it was assumed that such molecular-like clusters may also exist on titanate structures. The common property of $\mathrm{CeO}_{2}$ rods and TNTs is that they both contain huge amounts of defects necessary for the stabilization of $\mathrm{Au}_{25}$ clusters. It cannot be ruled out the possibility that the stabilized $\mathrm{Au}_{25}$ cluster has a partial positive charge, these species may contribute to the higher binding energy tailing of $\mathrm{Au} 4 \mathrm{f}_{7 / 2}$ [80]. For comparison, the removal of thiolate ligands from the $\mathrm{Au}_{25}(\mathrm{SR})_{18} / \mathrm{CeO}_{2}$ rod catalyst resulted in three types of $\mathrm{Au}$ sites: $\mathrm{Au}^{\mathrm{n}+}(0<\mathrm{n}<1), \mathrm{Au}^{+}$, $\mathrm{Au}^{\mathrm{n}-}(0<\mathrm{n}<1)$ [85]. No negatively charged $\mathrm{Au}$ (indicated by a binding energy peak below the metallic Au position in the XP spectrum) was observed on titanate nanotubes.

The presence of positively charged Au atom (in ionexchange position of TNT) and the small cluster in $\mathrm{Au}_{25}$, possibly in positive charge strongly contribute to the enhanced activity of TNT in the photo-induced transformation of $\mathrm{CH}_{4}$ and the photo-initiated reaction of $\mathrm{CH}_{4}+\mathrm{CO}_{2}$ with and without $\mathrm{H}_{2} \mathrm{O}[123,125]$. The adsorbed methane may be directly activated by small Au clusters and ions. The gold adatom also increased the activity of TNT in the $\mathrm{CO}_{2}$ hydrogenation toward methane [80]. While $\mathrm{Au}_{25}$ clusters and $\mathrm{Au}$ ions cannot be formed on titania we attribute the high activity of $\mathrm{Au} / \mathrm{TNT}$ to the presence of $\mathrm{Au}_{25}$ and mainly to $\mathrm{Au}^{+}$ions. Both kind of ions may increase the separation of hole-pair and the activation of $\mathrm{CO}_{2}$ leading to methane formation.

As it was discussed previously in this review, the metal/ oxide interface plays a crucial role in heterogeneous catalysis and gives us the opportunity to design our catalysts by designing new active interfaces. This will be discussed in the next chapter.

\section{The Unique Catalytic Chemistry of the Oxide-Metal Interfaces}

\subsection{Adsorbates Induced Surface Reconstruction}

The atoms at the surface of a solid (as catalyst) assume a different structure than that of the bulk. The arrangement of the surface atoms may be due to the adsorption or surface reaction. It is generally accepted that the adsorption enthalpy is sufficient in many cases to break the bonds between surface atoms of the metals. Surfaces that undergo chemisorption generally result in more extensive reconstructions than those that undergo physisorption, as the breaking and formation of bonds between the surface atoms alter the interaction of the substrate atoms as well as the adsorbate. This fact may lead to the surface reconstruction of the metal structures. Surface reconstructions are important in that they help in the understanding of surface chemistry for various materials, especially in the case where another material is adsorbed onto the surface. $\operatorname{Pt}(110)$ [126-128] and $\operatorname{Pt}(111)$ [129, 130] surfaces are good examples for this reconstruction when small molecules (CO, $\mathrm{NO}, \mathrm{CN}$ groups) are bonded strongly to the surface. Adsorption of $\mathrm{CO}$ on $\mathrm{Pt}(110)$ in temperature range $300^{<} \mathrm{T}^{<} 500 \mathrm{~K}$ caused the $(1 \times 2)$ LEED pattern to change to a $(1 \times 1)$. Upon desorption of $\mathrm{CO}$ at $500 \mathrm{~K}$ or a higher temperature the $(1 \times 2)$ pattern repaired. This kind of periodicity may lead to the catalytic oscillation reaction $[131,132]$. The reconstruction is a well-documented phenomenon also in the field of catalytically active oxide support, for example in the titania catalysis [133].

\subsection{Adsorbate Induced Morphology Changes of Supported Nanoparticles}

The change of the morphology of supported metal nanoparticles in ambient gas atmospheres is of great interest, because this process is decisively important in the heterogeneous catalysis [134-136]. It is widely accepted that gases adsorbed strongly on the particles can induce morphological changes of supported metal nanoclusters. A special case of the particle restructuring on the effect of gas adsorption is the so-called oxidative disruption and reductive agglomeration of the supported noble metal nanoparticles [137-140]. In these studies, several structure sensitive methods were applied, like EXAFS, FTIR, STM.

CO-induced disruption and agglomeration was studied among others by STM over Pt deposited on a $\mathrm{TiO}_{2}(110)-(1 \mathrm{xn})$ surface at two coverages and annealed gently at $400 \mathrm{~K}$ [140]. Resulted obtained at $0.02 \mathrm{ML}$ of Pt coverage shown on the left side of Fig. 10a-d.

The characteristic area imaged before the $\mathrm{CO}$ treatments exhibits Pt nanoparticles of 1-2 nm distributed homogeneously (Fig. 10a). On the effect of $\mathrm{CO}$ exposure (10 min, $10^{-3}$ mbar) the particles of $1-2 \mathrm{~nm}$ totally disappeared; only very finally dispersed dots can be seen (Fig. 10b). This feature can be regarded as a sign for disintegration (disruption) of Pt nanoparticles. This tendency reverses however, as the exposure of $\mathrm{CO}$ increases $\left(10 \mathrm{~min}, 10^{-1} \mathrm{mbar}\right)$ : the 1-2 nm particles reappear with nearly the same concentration (Fig. 10c). At higher $\mathrm{CO}$ exposure (10 min, $10 \mathrm{mbar}$ ), the agglomeration of the particles proceeds and a few larger particles $(2-3 \mathrm{~nm})$ are readily observed. 

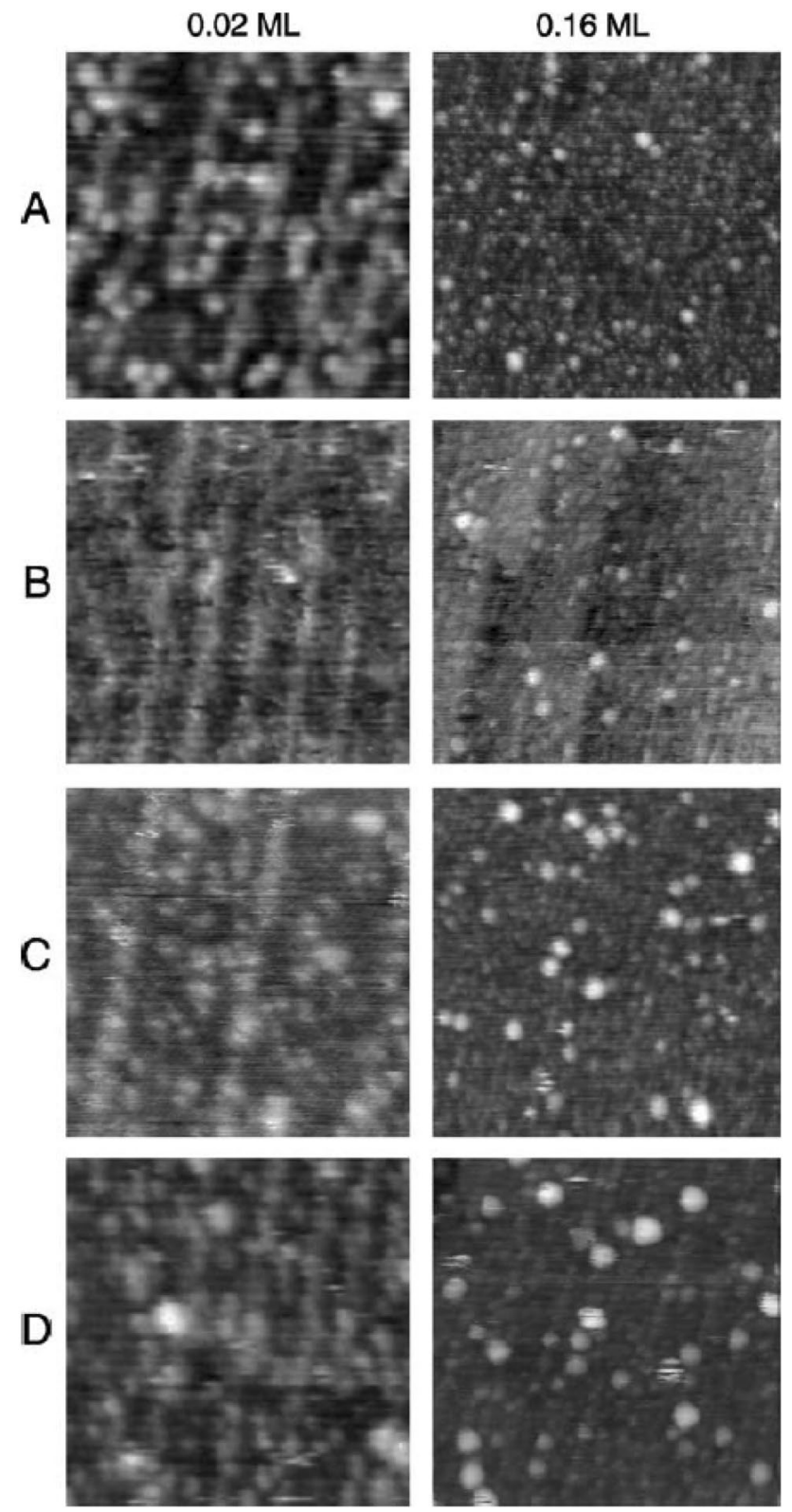

Fig. 10 Effects of CO-exposure at $300 \mathrm{~K}$ on $\mathrm{Pt} / \mathrm{TiO}_{2}\left(\begin{array}{lll}1 & 1 & 0\end{array}\right)-(1 \mathrm{xn})$ surface for two different metal coverages: $0.02 \mathrm{ML}, 0.16 \mathrm{ML}$. a Initial morphology of the model catalysts; after $10 \mathrm{~min}$ exposure of CO b $10^{-3}$ mbar, c $10^{-1} \mathrm{mbar}$, d $10 \mathrm{mbar}$. The size of the images: $20 \mathrm{~nm} \times 20 \mathrm{~nm}$ (left), $50 \mathrm{~nm} \times 50 \mathrm{~nm}$ (right). (Reproduced from Reference [140])

The same CO treatment was performed for the model catalyst containing 0.16 ML Pt (Fig. 10, right side). Before $\mathrm{CO}$ treatment, the size of the $\mathrm{Pt}$ particles varied in the range of $1-3 \mathrm{~nm}$ (Fig. 10a). Exposing this surface to $\mathrm{CO}$ $\left(10 \mathrm{~min}, 10^{-3} \mathrm{mbar}\right)$ at $300 \mathrm{~K}$, only very limited change of the morphology on the surface was observed: the concentration of the larger nanoparticles increased to some extent (Fig. 10b). A significant increase in the average particle size was experienced, however, on the effect of further $\mathrm{CO}$ exposure $\left(10^{-1} \mathrm{mbar}, 10 \mathrm{~min}\right)$ : the concentration and the average size of the larger particles increased by a factor of two (Fig. 10c). The disruption and reductive agglomeration of the supported noble metal nanoparticles was explained by $\mathrm{CO}$-assisted Ostwald ripening, in which the mass transport proceeds via surface carbonyl intermediates [134-140]. The STM results show that the adsorption-induced processes are a size dependent reaction. The driving force behind this process is very probably the higher M-CO bond energy as compared to that of the M-M bond.

The local heat of adsorption or reaction enthalpy could be sufficient to destroy the bimetallic structures formed on titania or titanate substrates. Using surface sensitive techniques, it turned out that $\mathrm{Au}-\mathrm{Rh}, \mathrm{Au}-\mathrm{Pt}$ and $\mathrm{Au}-\mathrm{Pd}$ bimetallic systems form a core-shell structure, where the Au completely and uniformly covers the other metal nanoparticles. FTIR and LEIS studies demonstrated that $\mathrm{CO}$ adsorption promote the diffusion of $\mathrm{Rh}$ to the surface from the $\mathrm{Au}-\mathrm{Rh}$ bimetallic "core-shell" cluster formed on titanate nanotubes [141]. Similar phenomena was observed recently in the Au-Pt clusters on $\mathrm{TiO}_{2}(110)$ [142]. The same effect was found on $\mathrm{Au}-\mathrm{Pd}$ bimetallic model catalysts, synthesized either as thin films on $\mathrm{Mo}(110)$ or as nanoparticles on $\mathrm{TiO}_{2}$ film in $\mathrm{CO}$ oxidation at elevated (8-16 Torr) CO pressures [143]. Pd preferentially segregates to the surface to form contiguous $\mathrm{Pd}$ sites and $\mathrm{CO}$ oxidation reactivity is regained.

\subsection{Electron Transfer and Spill-Over Phenomena at Metal-Oxide Interface}

The titania and other reducible oxides are very effective supports for many metal particles not only because of their high surface but they could shuttle electron transfer from and to the metal [144, 145]. The direction of electron transport depends on the electron negativity (work function) difference between metal and support. The electronic interaction between metal and oxide significantly contribute to the activity of the catalysts. Positively charged metal particles via electron transfer could be formed, which are performed higher activity as it was pointed out in the previous section.

Electron fluctuation from metal to reducible oxides $\left(\mathrm{CeO}_{2}, \mathrm{TiO}_{2}\right.$ and others) may change the concentration of oxygen vacancies. The highly active redox pair can increase the activation of adsorbed molecules. From this respect, the well-characterized $\mathrm{Ce}^{4+} / \mathrm{Ce}^{3+}$ redox pair that is able to enhance the dissociative activation of $\mathrm{CO}_{2}$ [146]. In addition to the intrinsic properties of cerium oxide, the morphology of the support with different preferentially exposed faces has been found to be crucial factor in many reactions, such as CO oxidation [147], NO reduction [148], methanol synthesis [149] and water gas shift reaction [150]. The source of face effect of ceria comes from difference of electronic properties and the concentration of oxygen vacancy. The 
other important physical chemical property of the reducible oxide support is its reducibility. Redox support such as ceria improves catalysts stability due to their high oxygen storage capacity and oxygen mobility. The easily accessible oxygen can react with carbon species as soon as it forms, and it keeps the metal surface free of carbon, thus inhibiting deactivation $[151,152]$. Oxygen spillover from ceria to metal particle is also an important factor in the increasing of the activity of catalysts $[14,153,154]$. Another important reaction step at the metal-oxide interface is the hydrogen spill-over phenomena. In this process, the hydrogen activates on metal surface and the "hot" hydrogen atom migrates to the oxide resulting in a higher reducibility $[155,156]$.

\subsection{Strong Metal-Support Interaction}

Much interest is currently expressed in titania as a support, mainly due to the interesting observation that the reduction of $\mathrm{TiO}_{2}$-supported metals at or above $773 \mathrm{~K}$ suppresses $\mathrm{H}_{2}$ and $\mathrm{CO}$ adsorption $[136,149]$. The term strong metal-support interaction (SMSI) is commonly associated with the original observation of Tauster and co-workers. As a possible explanation, the authors first suggested electronic effects via charge transfer and even rejected metal encapsulation, which is now considered as the main manifestation of SMSI, based on recent advanced electron spectroscopy studies [157]. Despite enormous efforts to directly visualize the encapsulation process, the precise mechanism of encapsulation remains unknown.

Thermodynamic considerations favor oxide spillover onto the metal surface rather than migration through the metal particle and subsequent segregation to the surface. Although the metal/ $/ \mathrm{TiO}_{2}$ system remains the classic example of SMSI via encapsulation, several other combinations of reducible transition metal oxides (TMO) and metals have shown similar behaviour [158, 159]. Figure 11 demonstrates a STM experimental series for Rh mobility resulting coalescence and the build-up of $\mathrm{TiO}_{\mathrm{x}}$ overlayers on $\mathrm{Rh}$ particles as a function of temperature [159].

The deposition of $0.03 \mathrm{ML}$ of $\mathrm{Rh}$ at $330 \mathrm{~K}$ onto a $\mathrm{TiO}_{2}(110)-(1 \times 2)$ surface and annealing at $850 \mathrm{~K}$ for $10 \mathrm{~min}$ results in 1-2 atomic layer thick $\mathrm{Rh}$ nanoparticles with a diameter of $\sim 1.5 \mathrm{~nm}$ (Fig. 10a). The particles preferentially occupy the bright rows identified with a reduced 1D phase $\left(\mathrm{Ti}_{2} \mathrm{O}_{3}\right)$. The $\mathrm{Rh}$ particles post grown at $850 \mathrm{~K}$ (deposition of an additional $0.25 \mathrm{ML} \mathrm{Rh}$ onto the surface characterized in Fig. 10a) are mostly of round shape (Fig. 10b).

The same sequence of experiments was also performed at $950 \mathrm{~K}$ (instead of $850 \mathrm{~K}$, before) (Fig. 10c, d). It can be observed that nearly round $\mathrm{Rh}$ nanoparticles are formed after the deposition of Rh $(0.05 \mathrm{ML})$ at $330 \mathrm{~K}$ and annealing of the probe at $950 \mathrm{~K}$ for $10 \mathrm{~min}$ (Fig. 10c). The average

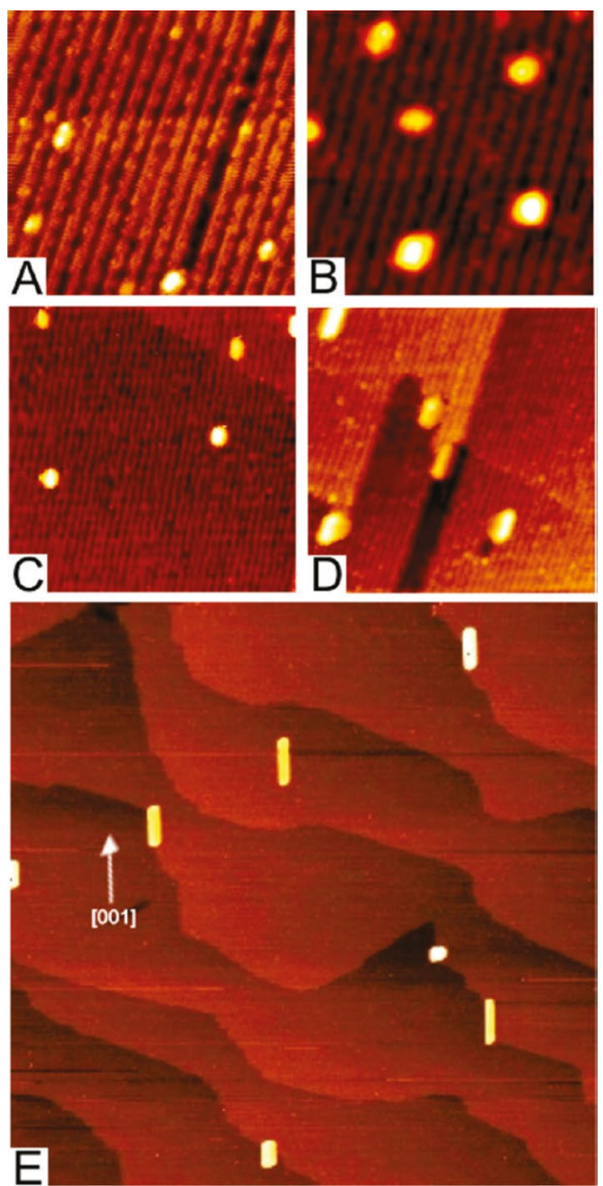

Fig. 11 The morphology of $\mathrm{Rh} / \mathrm{TiO}_{2}(110)-(1 \times 2)$ surfaces prepared by different treatments and detected by STM in cc mode: (A) deposition of $0.03 \mathrm{ML}$ of $\mathrm{Rh}$ at $330 \mathrm{~K}$, followed by $10 \mathrm{~min}$ annealing at $850 \mathrm{~K}$; (B) after deposition of additional $0.25 \mathrm{ML} \mathrm{Rh}$ at $850 \mathrm{~K}$ onto the surface imaged in part $\mathrm{A}$; (C) deposition of $0.05 \mathrm{ML}$ of $\mathrm{Rh}$ at $330 \mathrm{~K}$, followed by $10 \mathrm{~min}$ annealing at $950 \mathrm{~K}$; (D) after deposition of an additional $0.30 \mathrm{ML} \mathrm{Rh}$ at $950 \mathrm{~K}$ onto the surface imaged in part C. Image sizes: (A, B) $20 \times 20 \mathrm{~nm}^{2},(C, D) 50 \times 50 \mathrm{~nm}^{2}$. (E) STM image of $400 \times 400 \mathrm{~nm}^{2}$ recorded on $\mathrm{TiO}_{2}(110)-(1 \times 1)$ deposited by $\mathrm{Rh}(0.30 \mathrm{ML})$ at $1050 \mathrm{~K}$. (Reproduce from [159]) Reference

diameter of these nanoparticles is $3 \mathrm{~nm}$, and they consist of 2-3 atomic layers. The postdeposition of $\mathrm{Rh}$ at $950 \mathrm{~K}$ results in mainly elongated particles, independently of their location (Fig. 10d). Strongly elongated Rh nanoparticles were formed at high probability after the deposition of $\mathrm{Rh}$ at $1050 \mathrm{~K}$ (without seeding before) onto an unreconstructed titania surface, as is shown in a large-scale STM image of 400-400 nm (Fig. 10e).

Low energy ion scattering spectroscopy (LEIS) is sensitive almost exclusively to the topmost layer if noble gas ions are used. The complete absence of the Rh peak after annealing at $900 \mathrm{~K}$ for $1 \mathrm{~min}$ (Fig. 11) is a clear sign of the complete encapsulation of rhodium by the oxide [160]. An alternative explanation for the disappearance of $\mathrm{Rh}$ signal might be that all the rhodium diffused into the bulk of titania. This is ruled out 


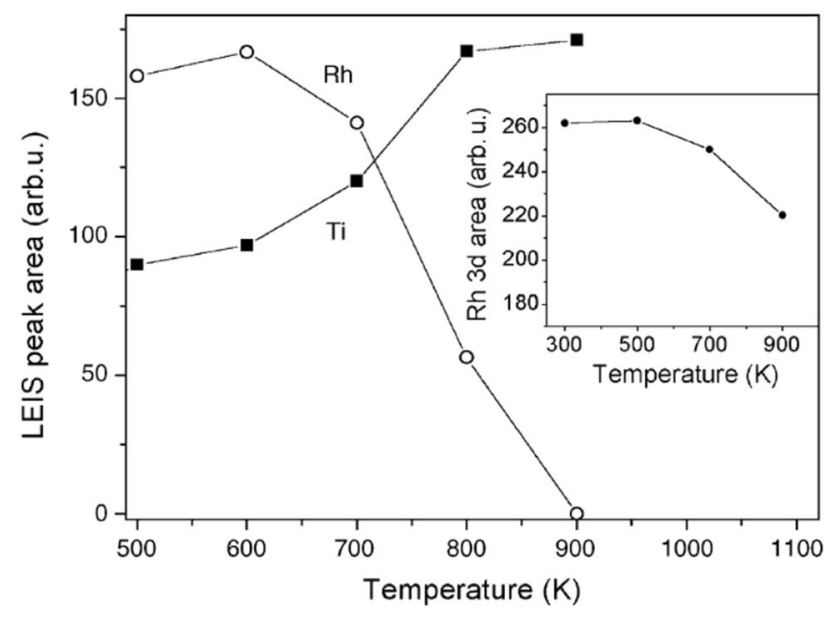

Fig. $12 \mathrm{Rh}$ and Ti LEIS peak areas obtained the $0.8 \mathrm{ML} \mathrm{Rh} / \mathrm{TiO}_{2}$ surface to different temperatures for $1 \mathrm{~min}$. Rhodium was deposited at $300 \mathrm{~K}$. Inset: area of the Rh $3 \mathrm{~d}$ XP doublet annealing at different temperatures. (Reproduce from [160]) Reference

by the fact that annealing at $900 \mathrm{~K}$ decreased only slightly the area of the Rh 3d doublet (inset of Fig. 11) (Fig. 12).

\section{Challenges of Bimetallic Nanoparticle Catalytic Chemistry}

Bimetallic catalysts started to gain significant commercial interest in 1960s for their use in hydrocarbon reforming in Exxon Research and Engineering Company [161]. The term "bimetallic clusters" has chosen by John H. Sinfelt for highly dispersed supported bimetallic systems in which interaction between two metals is indicated. Bimetallic catalysts often show electronic and chemical properties that differ from their individual counterparts offer enhanced selectivity, activity and stability [162]. Two mechanisms that contribute to the modification of the electronic and chemical properties of these systems have been proposed. First, the formation of heterometallic bonds changes electronic environment of the metal surface through ligand effect. Second, in bimetallic structure, the average metal-metal bond lengths changes than that of constituent metals resulting in strain effect that changes the electronic structure of the metal [163].

It is challenging to distinguish the two effects if both playing a role. The electronic and chemical properties of bimetallic catalysts can be tuned through changes in composition of host and guest metals. Current synthetic protocols allow careful adjustment of nanoparticles (NPs) size, shape and composition [164]. The preparation of bimetallic catalysts has been reviewed and summarized by various authors [164-167]. The molecular or atomic level understanding is very important because it will help us to uncover the catalytic mechanisms on the surface of bimetallic catalysts.
Electron microscopy [168-170], scanning tunnelling microscopy [171, 172], electron spectroscopy [173, 174], vibrational spectroscopy [175-178], X-ray absorption spectroscopy [179-182] have been used for structure identification of bimetallic catalysts. It has been demonstrated that the surface structure and composition of the bimetallic catalysts under reactive environment differ from those realised using high vacuum techniques $[183,184]$.

Under reactive environment (high temperature and pressure), bimetallic catalysts can undergo various changes such as surface segregation [185-187], phase transformation [188] and selective oxidation of one of the bimetallic catalysts [189]. The advent of several in situ techniques can be helpful to identify the surface structure and composition of bimetallic catalysts under reaction conditions [171, 190-200]. Surface sensitive spectroscopic and microscopic techniques such as Near Ambient-Pressure X-ray Photoelectron Spectroscopy (NAP-XPS), X-ray Absorption Spectroscopy (XAS), high-pressure scanning tunnelling microscopy, transmission electron microscopy, scanning transmission x-ray microscopy have been used for this purpose. The unique chemical and physical properties of active components emerge from the interactions of their surfaces with the reactive environments. The presence of complexity of the solid-gas and solid-liquid interfaces under reactive environments in heterogeneous catalytic system and their structural and compositional changes make understanding catalytic mechanisms extremely challenging.

In the following we will review some of the bimetallic systems that undergo structural and chemical changes under reactive environments. Tao and co-workers prepared core-shell $\mathrm{Rh}_{0.5} \mathrm{Pd}_{0.5}$ and $\mathrm{Pt}_{0.5} \mathrm{Pd}_{0.5}$ bimetallic nanoparticles by colloidal chemistry method and studied in situ the structure and composition under reaction conditions in different gas environments using AP-XPS [201]. Depth-profile analysis using X-ray energies of $1486.6 \mathrm{eV}, 850 \mathrm{eV}$ and $645 \mathrm{eV}$ corresponding to mean free paths of approximately 1.6, 1.0, and $0.7 \mathrm{~nm}$ revealed $\mathrm{Rh}$ atomic fractions of $0.52 \pm 0.03$, $0.86 \pm 0.03$ and $0.93 \pm 0.03$ respectively. $R$ h rich shell and Pd rich core were recognised (Fig. 13a). The surface composition and chemical state of the $\mathrm{Rh}_{0.5} \mathrm{Pd}_{0.5}$ bimetallic nanoparticles were studied under oxidizing (100 mtorr $\mathrm{NO}$ or $\mathrm{O}_{2}$ ), catalytic (100 mtorr $\mathrm{NO}$ and 100 mtorr $\mathrm{CO}$ ) and reducing (100 mtorr $\mathrm{CO}$ or $\mathrm{H}_{2}$ ) conditions by means of AP-XPS. The atomic fractions were obtained with an X-ray energy of $645 \mathrm{eV}$, which corresponds to $0.7 \mathrm{~nm}$ shell (Fig. 13b). The top part of Fig. 13b shows a considerable fluctuation of the relative atomic fractions as the gas environment changed from oxidizing to catalytic at $300{ }^{\circ} \mathrm{C}$. In oxidizing condition, the $\mathrm{Rh}$ in the shell was almost completely oxidized with $\sim 94 \%$ of the $\mathrm{Rh}$ in $\mathrm{RhO}_{\mathrm{y}}$ form. In reducing condition, total $\mathrm{Rh}$ atomic fraction in the shell decreased from $0.92 \pm 0.03$ to $0.46 \pm 0.02$ and $\mathrm{Pd}$ atomic fraction in the core 


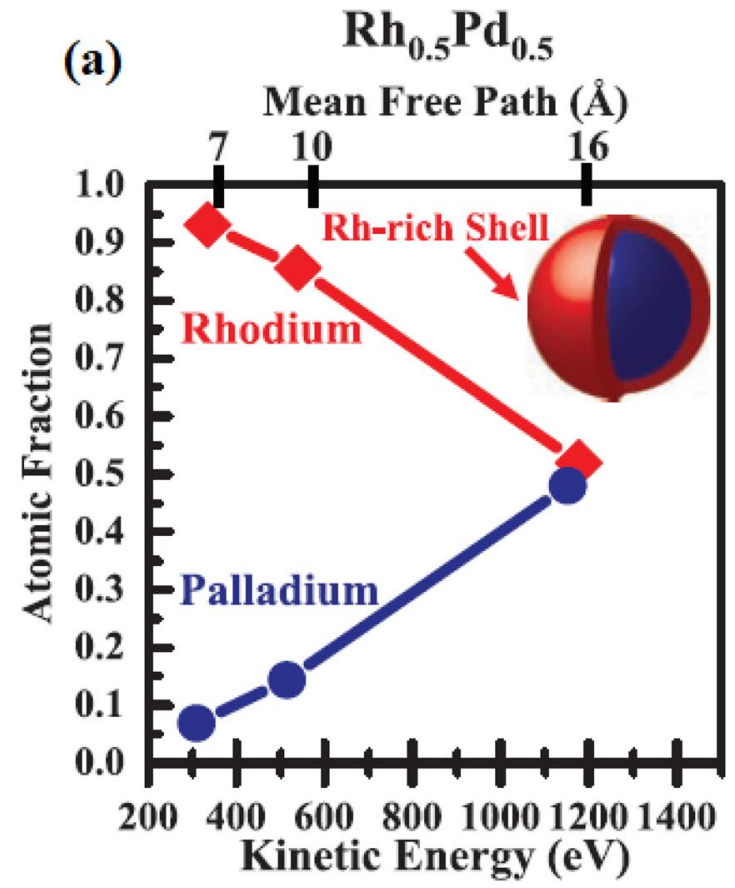

Fig. 13 a Surface structure of as-synthesized $\mathrm{Rh}_{0.5} \mathrm{Pd}_{0.5}$ and $\mathbf{b}$ (top) evolution of $\mathrm{Rh}\left(\mathrm{Rh}^{0}+\mathrm{Rh}^{2 \mathrm{y}+}\right)$ and $\mathrm{Pd}\left(\mathrm{Pd}^{0}+\mathrm{Pd}^{2 \mathrm{y}+}\right)$ atomic fractions in the $\mathrm{Rh}_{0.5} \mathrm{Pd}_{0.5} \mathrm{NPs}$ at $300{ }^{\circ} \mathrm{C}$ under oxidizing conditions (100 mtorr $\mathrm{NO}$ or $\mathrm{O}_{2}$ ) and catalytic conditions (100 mtorr NO and 100 mtorr $\mathrm{CO}$ ) denoted in the $\mathrm{x}$ axis. (Bottom) Evolution of the fraction of the oxidized Rh (left y axis) and Pd atoms (right y axis) in the examined region under the same reaction conditions as the top part of the fig-

increased from $0.08 \pm 0.03$ to $0.54 \pm 0.02$ (reaction 2 in top part of Fig. 13b). This result shows that the Pd migrated to the shell and $\mathrm{Rh}$ migrated to the core and $\mathrm{RhO}_{\mathrm{y}}$ reduced to metal $\mathrm{Rh}^{0}$. When the reaction is changed to oxidizing condition (reaction 3 in top part of Fig. 13b), Rh diffuses back to the shell and oxidized. The reconstructed shell contains $\sim 72 \pm 3 \% \mathrm{Rh}$, of which $\sim 90 \%$ is oxidized. If reducing condition is introduced again, the chemical composition restored as that of reaction 2 in top part of Fig. 13b. The opposite segregation behaviour of $\mathrm{Rh}$ and $\mathrm{Pd}$ under oxidizing and reducing conditions can be explained by considering the surface energy in the metals and in the oxides. The lower surface energy of Pd comparative to $\mathrm{Rh}$ tends to move $\mathrm{Pd}$ metal atoms to the surface. This is since Rh oxide is more stable than the Pd oxide provides the driving force for the segregation and preferential oxidation of $\mathrm{Rh}$ at the surface. In reducing conditions, the oxides are reduced to the metal and the oxygen atoms react with adsorbed $\mathrm{CO}$ to form $\mathrm{CO}_{2}$. $\mathrm{Rh}$ atoms migrate to the core because of its higher surface free energy and thus decreasing the atomic fraction of $\mathrm{Rh}$ in the shell under reducing and catalytic conditions.

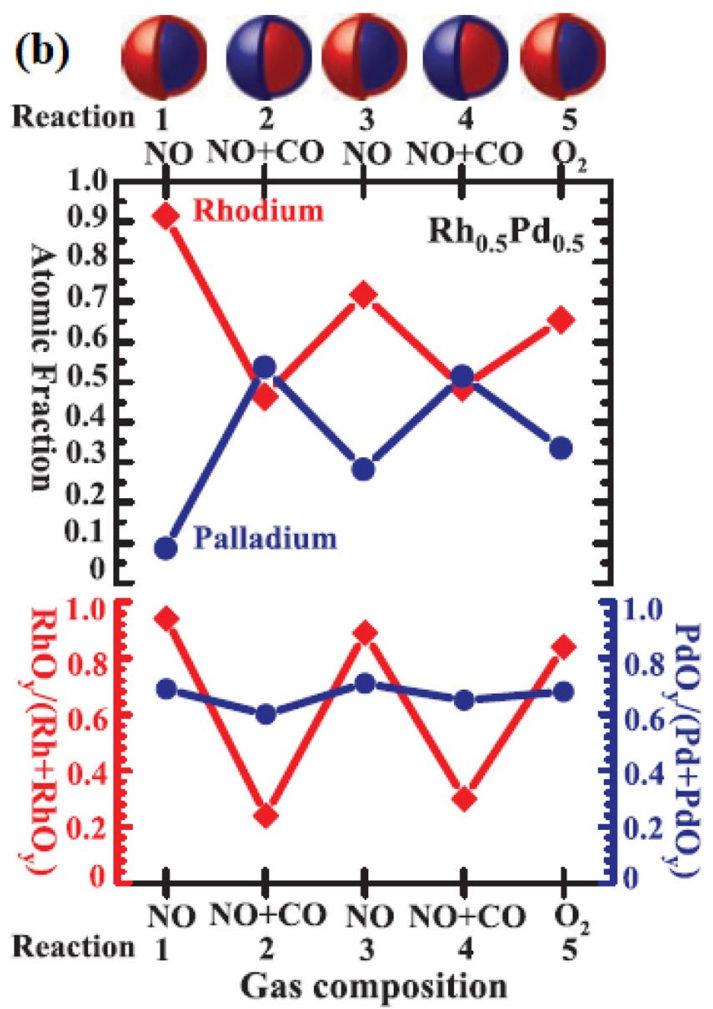

ure. All atomic fractions in this figure were obtained with an $\mathrm{x}$-ray energy of $645 \mathrm{eV}$ for Rh3d and $\mathrm{Pd} 3 \mathrm{~d}$, which generates photoelectrons with a MFP of $\sim 0.7 \mathrm{~nm}$. Schematic diagrams above the top of the figure show the reversible segregation of $\mathrm{Rh}$ and $\mathrm{Pd}$ under alternating oxidizing and catalytic conditions. The y-axis data points for reactions 1,3 , and 5 have an associated error of \pm 0.03 ; for reactions 2 and 4 , the error bar is \pm 0.02 . (Reproduced from Reference [201])

Alayoglu and co-workers studied the $\mathrm{Au}_{\mathrm{x}} \mathrm{Pd}_{1-\mathrm{x}}(\mathrm{x}=0$, $0.25,0.5,0.75,1)$ bimetallic nanoparticle restructuring during CO oxidation using AP-XPS [202]. Both STEM/EDS phase mapping and XPS depth-profiles display that the assynthesized $\mathrm{Au}_{\mathrm{x}} \mathrm{Pd}_{1-\mathrm{x}}(\mathrm{x}=0.25,0.5,0.75)$ bimetallic nanoparticles exhibit core-shell structures with Pd-rich shells and Au-rich cores. The atomic fractions of $\mathrm{Au}_{0.25} \mathrm{Pd}_{0.75}$, $\mathrm{Au}_{0.5} \mathrm{Pd}_{0.5}$, and $\mathrm{Au}_{0.75} \mathrm{Pd}_{0.25}$ bimetallic nanoparticles under vacuum and various gas atmospheres are displayed in Fig. 14. STEM/EDS spectra reveal that with the increase in $\mathrm{Au}$ concentration, the Au core size increases while Pd shell thickness decreases. AP-XPS studies indicate that the surface composition for the $\mathrm{Au}_{0.25} \mathrm{Pd}_{0.75}$ and $\mathrm{Au}_{0.5} \mathrm{Pd}_{0.5}$ bimetallic nanoparticles with relatively thick Pd shells remain unaffected under vacuum, reactive gas atmospheres and $\mathrm{CO}$ oxidation reaction at $200{ }^{\circ} \mathrm{C}$. However, the $\mathrm{Au}_{0.75} \mathrm{Pd}_{0.25}$ bimetallic nanoparticles restructures irreversibly to Au-rich surface state at $200{ }^{\circ} \mathrm{C}$ under $\mathrm{CO}$ oxidation reaction.

The turnover frequency versus surface composition were studied and observed that all bimetallic nanoparticles exhibit higher turnover frequency than monometallic $\mathrm{Au}$ 


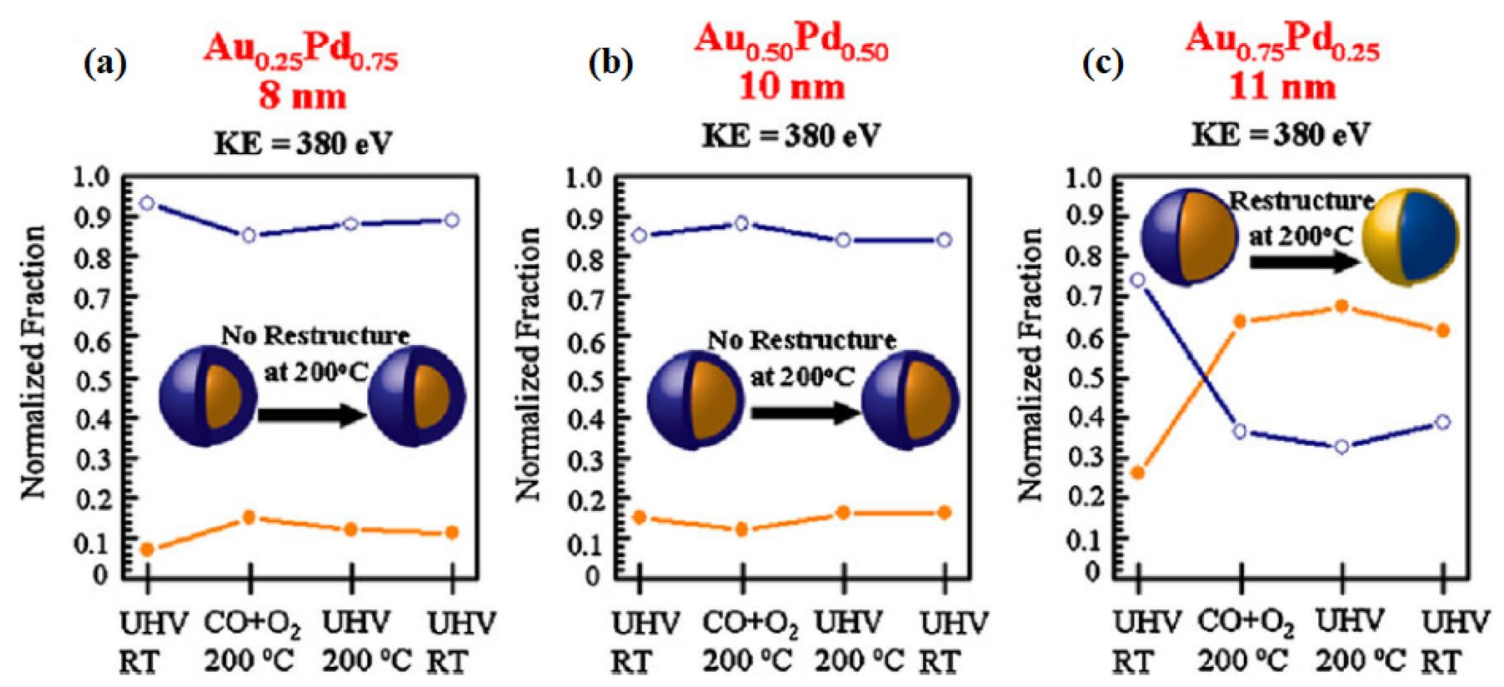

Fig. 14 Normalized Pd (blue) and Au (gold) fractions are plotted versus various temperatures and pressure (i.e., $\mathrm{CO}$ oxidation reaction) conditions from ambient pressure XPS analysis using $380 \mathrm{eV}$ X-rays

or Pd nanoparticles. $\mathrm{Au}_{0.25} \mathrm{Pd}_{0.75}$ bimetallic nanoparticle showed highest turnover frequency than the $\mathrm{Au}_{0.5} \mathrm{Pd}_{0.5}$ and $\mathrm{Au}_{0.75} \mathrm{Pd}_{0.25}$ bimetallic nanoparticles. However, $\mathrm{Au}_{0.75} \mathrm{Pd}_{0.25}$ bimetallic nanoparticle displayed excellent catalytic activity in $\mathrm{CO}$ oxidation reaction at $200{ }^{\circ} \mathrm{C}$. Because of larger adsorption energies of $\mathrm{CO}$ and $\mathrm{O}_{2}$ on $\mathrm{Pd}$ than on $\mathrm{Au}, \mathrm{Pd}$ segregates in $\mathrm{Au}_{0.25} \mathrm{Pd}_{0.75}$. However, on $\mathrm{Au}_{0.75} \mathrm{Pd}_{0.25}$, $\mathrm{Au}$ forms thin shells at $200{ }^{\circ} \mathrm{C}$ and covers the nanoparticle surface so that $\mathrm{CO}$ and $\mathrm{O}_{2}$ could not bind on the Pd which is present in the inner shells. Due to the presence of thin Pd shells in the surface regions of the $\mathrm{Au}_{0.75} \mathrm{Pd}_{0.25}$ bimetallic nanoparticle, Au could easily exchange with Pd to segregate to the surface.

Musselwhite and co-workers studied the isomerization of n-hexane catalysed by supported Pt-Rh bimetallic nanoparticles [203]. $\mathrm{Pt}_{80} \mathrm{Rh}_{20}, \mathrm{Pt}_{90} \mathrm{Rh}_{10}$ with larger size $(6.5 \mathrm{~nm})$ hereafter referred to as $\mathrm{Pt}_{80} \mathrm{Rh}_{20}$ (6.5), $\mathrm{Pt}_{90} \mathrm{Rh}_{10}$ (6.5) and $\mathrm{Pt}_{80} \mathrm{Rh}_{20}$ with smaller size $(2.5 \mathrm{~nm})$ hereafter referred to as $\mathrm{Pt}_{80} \mathrm{Rh}_{20}$ (2.5) were prepared by colloidal chemistry approach. The overall TOF of $\mathrm{Pt}_{80} \mathrm{Rh}_{20}$ (6.5) was $0.013 \mathrm{~s}^{-1}$ and that of $\mathrm{Pt}_{90} \mathrm{Rh}_{10}$ (6.5) was $0.011 \mathrm{~s}^{-1}$. The isomer selectivity for $\mathrm{Pt}_{80} \mathrm{Rh}_{20}$ (6.5) and $\mathrm{Pt}_{90} \mathrm{Rh}_{10}$ (6.5) bimetallic nanoparticles were 44 and 55\% respectively. A plot of isomer TOF versus near surface composition is shown in Fig. 15. The maximum TOF was obtained on $\mathrm{Pt}_{90} \mathrm{Rh}_{10}$ (93/7 Pt/Rh surface composition) bimetallic nanoparticles. The maximum isomer formation occurs with the $\mathrm{Pt}$ to $\mathrm{Rh}$ atomic ratio of 1:5 in an ideal FCC (111) crystal face. This type of behaviour is termed as ensemble effect where the active metal is diluted with lesser active spacer atoms to increase the selectivity of the desired product. In this study, it was found that when $\mathrm{Pt}$ surface was diluted with a more active $\mathrm{Rh}$ atom, the $\mathrm{Rh}$ for $\mathbf{a} \mathrm{Au}_{0.25} \mathrm{Pd}_{0.75}, \mathbf{b} \mathrm{Au}_{0.5} \mathrm{Pd}_{0.5}$ and $\mathbf{c} \mathrm{Au}_{0.75} \mathrm{Pd}_{0.25}$ (Reproduced from Reference [202])

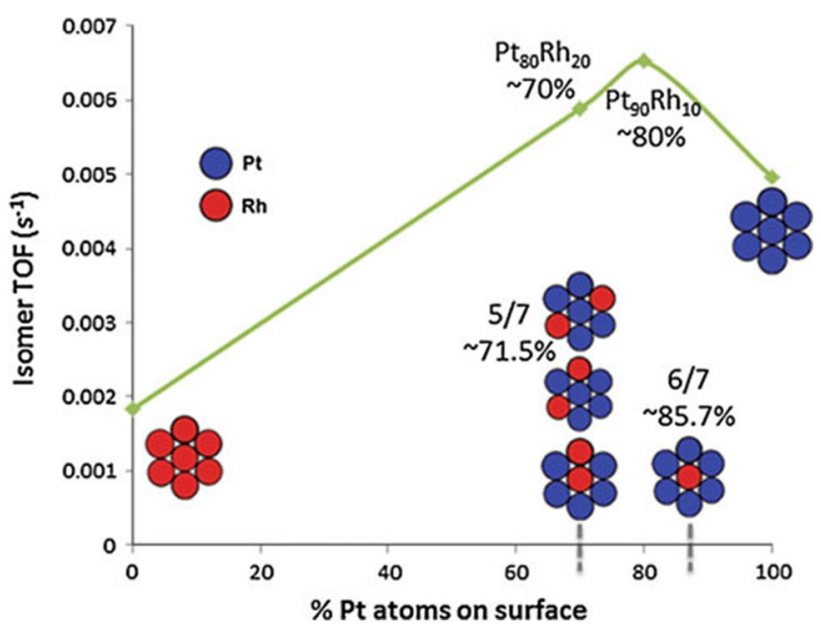

Fig. 15 Isomer TOF plotted against the near surface composition of the $6.5 \mathrm{~nm}$ NPs using AP-XPS. The maximum rate occurs on the bimetallic nanoparticles, where the surface ratio is $80: 20 \mathrm{Pt}: \mathrm{Rh}$. The dotted line represents what would be expected if a linear relationship existed with atomic composition. The actual data exhibits about a $60 \%$ increase in isomer TOF. This type of behavior can be attributed to an ensemble effect between the surface Pt and Rh atoms. The images shown are models for (111) fcc crystal facets (reproduced from Reference [203])

acts to activate the $\mathrm{C}-\mathrm{H}$ bond and the surrounding $\mathrm{Pt}$ atoms permit for the production of more desired isomer products.

The interaction of gold and rhodium was studied extensively on $\mathrm{TiO}_{2}(110)$ and titania-based oxide support recently [124, 141, 204-206]. The coadsorbed layer were prepared on nearly stoichiometric titania surface by physical vapor deposition (PVD) and by impregnation methods on titania 


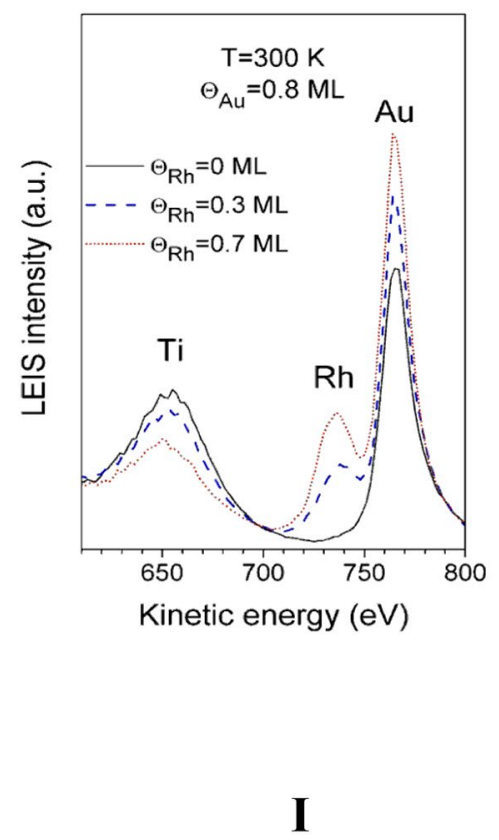

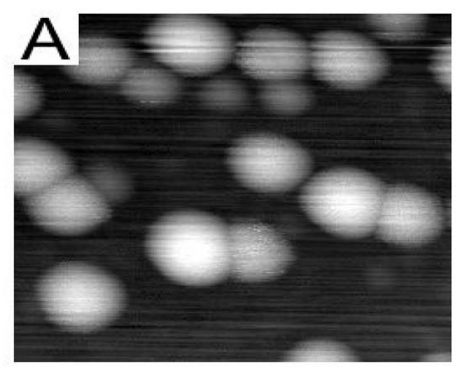
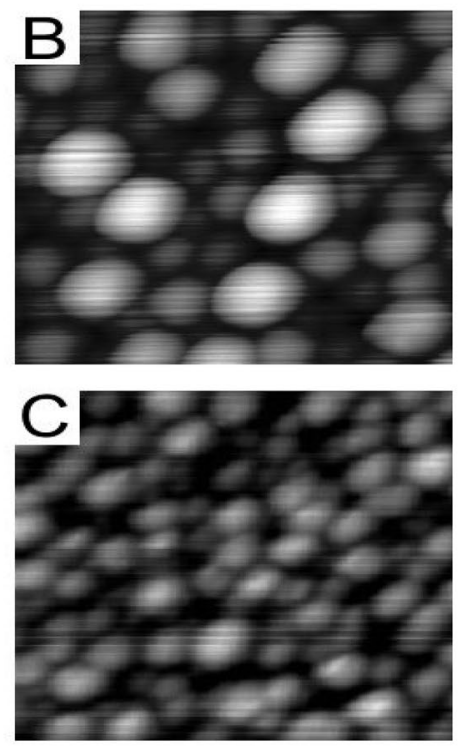

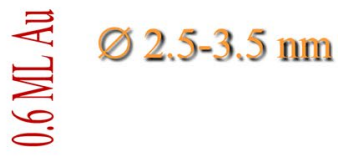

龸 $\sum_{0}^{\varnothing 3-4 \mathrm{~nm}}$

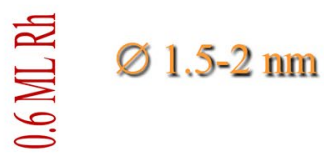

\section{II}

Fig. 16 (I) LEIS spectra of the 0.8 eqML $\mathrm{Au} / \mathrm{TiO}_{2}(110)$ surface and those obtained after subsequent $\mathrm{Rh}$ deposition deposition. (II) Characteristic STM images of $20 \times 20 \mathrm{~nm}^{2}$ recorded on (a) a $\mathrm{TiO}_{2}(110)$ surface deposited by 0.6 eqML of $\mathrm{Au}$ at $320-330 \mathrm{~K}$; b a surface

and titanates surfaces. The layer was characterized by lowenergy ion scattering (LEIS) and scanning tunneling microcopy (STM). It was found that because of the strong tendency of Au segregation in the Au-Rh bimetallic system, $\mathrm{Rh}$ atoms that impinged onto Au clusters pre-grown on $\mathrm{TiO}_{2}(110)$ became covered by gold atoms by place exchange or surface diffusion even at room temperature. The incorporation of rhodium led to an increase in the number of $\mathrm{Au}$ atoms on the outermost layer of metal clusters evidenced by LEIS (Fig. $16 \mathrm{I}$ ) and addition to this it leads to a slight enlargement of gold clusters indicated by STM (Fig. 16 II). A core-shell structure was formed, and it is plausible that if the gold completely and uniformly covers the Rh nanoparticles. The observed effect on the bimetallic nanoclusters is attributed to the different surface free energies of metals. For $\mathrm{Au}$, this value is much smaller than for $\mathrm{Rh}$, which provides a driving force for the bimetallic clusters to be covered by gold atoms. Interestingly, the stability of structure was sensitive against reactants for example $\mathrm{CO}$ adsorption. The adsorption formed by postdeposition of 0.6 eqML of $\mathrm{Rh}$ on the former Au covered surface; and $\mathbf{c}$ a $\mathrm{TiO}_{2}(110)$ surface deposited by 0.6 eqML of $\mathrm{Rh}$ at 320-330 K (reproduced from Reference [204])

of $\mathrm{CO}$ on $\mathrm{Au}-\mathrm{Rh}$ clusters may promote the diffusion of $\mathrm{Rh}$ to the surface of the cluster indicated by the appearance of $\mathrm{CO}$ bands attributable for $\mathrm{Rh}$ sites and due to $\mathrm{CO}$ adsorption, the Rh LEIS signal regained as it was demonstrated in previous chapter.

\section{Conclusions}

Size and shape dependent catalytic chemistry is of great interest and importance for designing highly active and selective catalysts. Although particle size has a major effect on catalytic activity, other factors such as oxidation state of the metal NPs and presence of low coordinated step and corner sites are also playing significant role. Crystals with high index facets exhibit superior reactivities owing to the presence of high-density atomic steps, edges and kinks which are usually considered active sites for chemical bond breaking. Metal NPs immobilised on support enhances their stability 
and spatial distribution. Unusual high catalytic activity can be obtained by tuning the metal-support interfaces. The insitu characterization techniques can be useful to track the structural changes of catalysts under reaction conditions.

Acknowledgements AS gratefully acknowledges the support of the Bolyai Janos Research Fellowship of the Hungarian Academy of Science and the "UNKP-20-5-SZTE-663" New National Excellence Program of the Ministry for Innovation and Technology. AK, and KZ is grateful for the fund of NKFIH (OTKA) K112531 \& NN110676 and K120115, respectively. The financial support of the Hungarian National Research, Development, and Innovation Office through the GINOP-2.3.2-15-2016-00013 project "Intelligent materials based on functional surfaces - from syntheses to applications" and the Ministry of Human Capacities through the EFOP-3.6.1-16-2016-00014 project and the 20391-3/2018/FEKUSTRAT are acknowledged. Authors are grateful for Zita Sandor for manuscript preparation assistance.

\section{References}

1. Somorjai GA, Li Y (2010) Introduction to surface chemistry and catalysis. Wiley, Hoboken

2. Ertl G (2010) Reactions at solid surfaces. Wiley, Hoboken. https ://doi.org/10.1002/9780470535295

3. Ross JRH (2012) Heterogeneous catalysis: fundamentals and applications. Elsevier, Amsterdam. https://doi.org/10.1016/ C2009-0-19388-1

4. Van Santen RA (2017) Modern heterogeneous catalysis: an introduction. Wiley, Hoboken. https://doi.org/10.1002/9783527810 253

5. Li Z, Ji S, Liu Y, Cao X, Tian S, Chen Y, Niu Z, Li Y (2020) Well-defined materials for heterogeneous catalysis: from nanoparticles to isolated single-atom sites. Chem Rev 120:623-682. https://doi.org/10.1021/acs.chemrev.9b00311

6. Linic S, Christopher P, Xin H, Marimuthu A (2013) Catalytic and photocatalytic transformations on metal nanoparticles with targeted geometric and plasmonic properties. Acc Chem Res 46:1890-1899. https://doi.org/10.1021/ar3002393

7. Liu L, Corma A (2018) Metal catalysts for heterogeneous catalysis: from single atoms to nanoclusters and nanoparticles. Chem Rev 118:4981-5079. https://doi.org/10.1021/acs.chemrev.7b007 76

8. Wang J, Wang G, Zhao J (2001) Density-functional study of Au n $(n=2-20)$ clusters: lowest-energy structures and electronic properties. Phys Rev B. https://doi.org/10.1103/PhysRevB.66.03541 8

9. Cao S, Tao FF, Tang Y, Li Y, Yu J (2016) Size- and shapedependent catalytic performances of oxidation and reduction reactions on nanocatalysts. Chem Soc Rev 45:4747-4765. https ://doi.org/10.1039/C6CS00094K

10. Goodman ED, Schwalbe JA, Cargnello M (2017) Mechanistic understanding and the rational design of sinter-resistant heterogeneous catalysts. ACS Catal 7:7156-7173. https://doi. org/10.1021/acsCatal7b01975

11. Graciani J, Mudiyanselage K, Xu F, Baber AE, Evans J, Senanayake SD, Stacchiola DJ, Liu P, Hrbek J, Sanz JF, Rodriguez JA (2014) Highly active copper-ceria and copper-ceria-titania catalysts for methanol synthesis from $\mathrm{CO}_{2}$. Science. https://doi. org/10.1126/science. 1253057

12. Kattel S, Yu W, Yang X, Yan B, Huang Y, Wan W, Liu P, Chen JG (2016) $\mathrm{CO}_{2}$ hydrogenation over oxide-supported PtCo catalysts: the role of the oxide support in determining the product selectivity. Angew Chem 128:8100-8105. https://doi. org/10.1002/ange.201601661

13. Senanayake SD, Ramírez PJ, Waluyo I, Kundu S, Mudiyanselage K, Liu Z, Liu Z, Axnanda S, Stacchiola DJ, Evans J, Rodriguez JA (2016) Hydrogenation of $\mathrm{CO}_{2}$ to methanol on $\mathrm{CeO}_{x} / \mathrm{Cu}(111)$ and $\mathrm{ZnO} / \mathrm{Cu}(111)$ catalysts: role of the metal-oxide interface and importance of $\mathrm{Ce}^{3+}$ sites. J Phys Chem C 120:1778-1784. https ://doi.org/10.1021/acs.jpcc.5b12012

14. Vayssilov GN, Lykhach Y, Migani A, Staudt T, Petrova GP, Tsud N, Skála T, Bruix A, Illas F, Prince KC, Matolı'n V, Neyman KM, Libuda J (2011) Support nanostructure boosts oxygen transfer to catalytically active platinum nanoparticles. Nat Mater 10:310-315. https://doi.org/10.1038/nmat2976

15. Nilius N, Ganduglia-Pirovano MV, Brázdová V, Kulawik M, Sauer J, Freund H-J (2008) Counting electrons transferred through a thin alumina film into Au chains. Phys Rev Lett 100:096802. https://doi.org/10.1103/PhysRevLett100.096802

16. Lin X, Nilius N, Freund H-J, Walter M, Frondelius P, Honkala K, Häkkinen H (2009) Quantum well states in two-dimensional gold clusters on $\mathrm{MgO}$ thin films. Phys Rev Lett 102:206801. https ://doi.org/10.1103/PhysRevLett102.206801

17. Mehta P, Greeley J, Delgass WN, Schneider WF (2017) Adsorption energy correlations at the metal-support boundary. ACS Catal 7:4707-4715. https://doi.org/10.1021/acsCatal7b00979

18. Kattel S, Yan B, Chen JG, Liu P (2016) $\mathrm{CO}_{2}$ hydrogenation on $\mathrm{Pt}, \mathrm{Pt} / \mathrm{SiO}_{2}$ and $\mathrm{Pt} / \mathrm{TiO}_{2}$ : importance of synergy between $\mathrm{Pt}$ and oxide support. J Catal 343:115-126. https://doi.org/10.1016/J. JCAT.2015.12.019

19. Fiévet F, Ammar-Merah S, Brayner R, Chau F, Giraud M, Mammeri F, Peron J, Piquemal J-Y, Sicard L, Viau G (2018) The polyol process: a unique method for easy access to metal nanoparticles with tailored sizes, shapes and compositions. Chem Soc Rev 47:5187-5233. https://doi.org/10.1039/C7CS00777A

20. An K, Somorjai GA (2012) Size and shape control of metal nanoparticles for reaction selectivity in catalysis. ChemCatChem 4:1512-1524. https://doi.org/10.1002/cctc.201200229

21. Min BK, Friend CM (2007) Heterogeneous gold-based catalysis for green chemistry: low-temperature $\mathrm{CO}$ oxidation and propene oxidation. Chem Rev 107:2709-2724. https://doi.org/10.1021/ cr050954d

22. Freund H-J, Meijer G, Scheffler M, Schlögl R, Wolf M (2011) CO oxidation as a prototypical reaction for heterogeneous processes. Angew Chem Int Ed 50:10064-10094. https://doi.org/10.1002/ anie. 201101378

23. Haruta M, Kobayashi T, Sano H, Yamada N (1987) Novel gold catalysts for the oxidation of carbon monoxide at a temperature far below $0{ }^{\circ} \mathrm{C}$. Chem Lett 16:405-408. https://doi.org/10.1246/ cl.1987.405

24. Valden M, Lai X, Goodman DW (1998) Onset of catalytic activity of gold clusters on titania with the appearance of nonmetallic properties. Science 281:1647. https://doi.org/10.1126/scien ce.281.5383.1647

25. Valden M, Pak S, Lai X, Goodman DW (1998) Structure sensitivity of $\mathrm{CO}$ oxidation over model $\mathrm{Au} / \mathrm{TiO}_{2}$ catalysts. Catal Lett 56:7-10. https://doi.org/10.1023/A:1019028205985

26. Schwartz V, Mullins DR, Yan W, Chen B, Dai S, Overbury SH (2004) XAS study of Au supported on $\mathrm{TiO}_{2}$ : influence of oxidation state and particle size on catalytic activity. J Phys Chem B 108:15782-15790. https://doi.org/10.1021/jp048076v

27. Guzman J, Gates BC (2004) Catalysis by supported gold: correlation between catalytic activity for $\mathrm{CO}$ oxidation and oxidation states of gold. J Am Chem Soc 126:2672-2673. https://doi. org/10.1021/ja039426e

28. Yoon B, Häkkinen H, Landman U, Wörz AS, Antonietti J-M, Abbet S, Judai K, Heiz U (2005) Charging effects on bonding 
and catalyzed oxidation of $\mathrm{CO}$ on Au8 clusters on $\mathrm{MgO}$. Science 307:403. https://doi.org/10.1126/science.1104168

29. Lopez N, Nørskov JK (2002) Catalytic CO oxidation by a gold nanoparticle: a density functional study. J Am Chem Soc 124:11262-11263. https://doi.org/10.1021/ja026998a

30. Lopez N, Janssens TV, Clausen B, Xu Y, Mavrikakis M, Bligaard T, Nørskov J (2004) On the origin of the catalytic activity of gold nanoparticles for low-temperature CO oxidation. J Catal 223:232-235. https://doi.org/10.1016/J.JCAT.2004.01.001

31. Shaikhutdinov SK, Meyer R, Naschitzki M, Bäumer M, Freund H-J (2003) Size and support effects for co adsorption on gold model catalysts. Catal Lett 86:211-219. https://doi. org/10.1023/A:1022616102162

32. Sanchez A, Abbet S, Heiz U, Schneider W-D, Häkkinen H, Barnett RN, Landman U (1999) When gold is not noble: nanoscale gold catalysts. J Phys Chem A 103:9573-9578. https://doi. org/10.1021/jp9935992

33. Lee S, Fan C, Wu T, Anderson SL (2004) CO oxidation on Aun/ $\mathrm{TiO}_{2}$ catalysts produced by size-selected cluster deposition. J Am Chem Soc 126:5682-5683. https://doi.org/10.1021/ja049436v

34. Chen MS, Goodman DW (2004) The structure of catalytically active gold on titania. Science 306:252. https://doi.org/10.1126/ science. 1102420

35. An N, Li S, Duchesne PN, Wu P, Zhang W, Lee J-F, Cheng S, Zhang P, Jia M, Zhang W (2013) Size effects of platinum colloid particles on the structure and $\mathrm{CO}$ oxidation properties of supported $\mathrm{Pt} / \mathrm{Fe}_{2} \mathrm{O}_{3}$ catalysts. J Phys Chem C 117:21254-21262. https://doi.org/10.1021/jp404266p

36. Grass ME, Zhang Y, Butcher DR, Park JY, Li Y, Bluhm H, Bratlie KM, Zhang T, Somorjai GA (2008) A reactive oxide overlayer on rhodium nanoparticles during $\mathrm{CO}$ oxidation and its size dependence studied by in situ ambient-pressure X-ray photoelectron spectroscopy. Angew Chem Int Ed 47:8893-8896. https:// doi.org/10.1002/anie.200803574

37. Joo SH, Park JY, Renzas JR, Butcher DR, Huang W, Somorjai GA (2010) Size effect of ruthenium nanoparticles in catalytic carbon monoxide oxidation. Nano Lett 10:2709-2713. https:// doi.org/10.1021/nl101700j

38. Jiao F, Li J, Pan X, Xiao J, Li H, Ma H, Wei M, Pan Y, Zhou Z, Li M, Miao S, Li J, Zhu Y, Xiao D, He T, Yang J, Qi F, Fu Q, Bao $X$ (2016) Selective conversion of syngas to light olefins. Science 351:1065. https://doi.org/10.1126/science.aaf1835

39. Khodakov AY, Chu W, Fongarland P (2007) Advances in the development of novel cobalt Fischer-Tropsch catalysts for synthesis of long-chain hydrocarbons and clean fuels. Chem Rev 107:1692-1744. https://doi.org/10.1021/cr050972v

40. Peng X, Cheng K, Kang J, Gu B, Yu X, Zhang Q, Wang Y (2015) Impact of hydrogenolysis on the selectivity of the Fischer-Tropsch synthesis: diesel fuel production over mesoporous zeolite-Y-supported cobalt nanoparticles. Angew Chem Int Ed 54:4553-4556. https://doi.org/10.1002/anie.201411708

41. Torres Galvis HM, Bitter JH, Khare CB, Ruitenbeek M, Dugulan AI, de Jong KP (2012) Supported iron nanoparticles as catalysts for sustainable production of lower olefins. Science 335:835. https://doi.org/10.1126/science.1215614

42. Li J, He Y, Tan L, Zhang P, Peng X, Oruganti A, Yang G, Abe H, Wang Y, Tsubaki N (2018) Integrated tuneable synthesis of liquid fuels via Fischer-Tropsch technology. Nat Catal 1:787-793. https://doi.org/10.1038/s41929-018-0144-z

43. Navarro V, van Spronsen MA, Frenken JWM (2016) In situ observation of self-assembled hydrocarbon Fischer-Tropsch products on a cobalt catalyst. Nat Chem 8:929-934. https://doi. org $/ 10.1038 /$ nchem.2613

44. Torres Galvis HM, Bitter JH, Davidian T, Ruitenbeek M, Dugulan AI, de Jong KP (2012) Iron particle size effects for direct production of lower olefins from synthesis gas. J Am Chem Soc 134:16207-16215. https://doi.org/10.1021/ja304958u

45. Bezemer GL, Bitter JH, Kuipers HPCE, Oosterbeek H, Holewijn JE, Xu X, Kapteijn F, van Dillen AJ, de Jong KP (2006) Cobalt particle size effects in the Fischer-Tropsch reaction studied with carbon nanofiber supported catalysts. J Am Chem Soc 128:39563964. https://doi.org/10.1021/ja058282w

46. Borg Ø, Dietzel PDC, Spjelkavik AI, Tveten EZ, Walmsley JC, Diplas S, Eri S, Holmen A, Rytter E (2008) Fischer-Tropsch synthesis: cobalt particle size and support effects on intrinsic activity and product distribution. J Catal 259:161-164. https ://doi.org/10.1016/J.JCAT.2008.08.017

47. Park J-Y, Lee Y-J, Khanna PK, Jun K-W, Bae JW, Kim YH (2010) Alumina-supported iron oxide nanoparticles as Fischer-Tropsch catalysts: effect of particle size of iron oxide. J Mol Catal A 323:84-90. https://doi.org/10.1016/J.MOLCA TA.2010.03.025

48. Carballo JMG, Yang J, Holmen A, García-Rodríguez S, Rojas S, Ojeda M, Fierro JLG (2011) Catalytic effects of ruthenium particle size on the Fischer-Tropsch Synthesis. J Catal 284:102-108. https://doi.org/10.1016/J.JCAT.2011.09.008

49. Ratnasamy C, Wagner JP (2009) Water gas shift catalysis. Catal Rev 51:325-440. https://doi.org/10.1080/01614940903048661

50. Zhai Y, Pierre D, Si R, Deng W, Ferrin P, Nilekar AU, Peng G, Herron JA, Bell DC, Saltsburg H, Mavrikakis M, Flytzani-Stephanopoulos M (2010) Alkali-stabilized Pt-OHx species catalyze low-temperature water-gas shift reactions. Science 329:1633. https://doi.org/10.1126/science.1192449

51. Yao S, Zhang X, Zhou W, Gao R, Xu W, Ye Y, Lin L, Wen X, Liu P, Chen B, Crumlin E, Guo J, Zuo Z, Li W, Xie J, Lu L, Kiely CJ, Gu L, Shi C, Rodriguez JA, Ma D (2017) Atomic-layered Au clusters on $\alpha$-MoC as catalysts for the low-temperature watergas shift reaction. Science 357:389. https://doi.org/10.1126/scien ce.aah4321

52. Yang M, Li S, Wang Y, Herron JA, Xu Y, Allard LF, Lee S, Huang J, Mavrikakis M, Flytzani-Stephanopoulos M (2014) Catalytically active $\mathrm{Au}-\mathrm{O}(\mathrm{OH}) \mathrm{x}$-species stabilized by alkali ions on zeolites and mesoporous oxides. Science 346:1498. https://doi. org/10.1126/science. 1260526

53. Zugic B, Zhang S, Bell DC, Tao F, Flytzani-Stephanopoulos M (2014) Probing the low-temperature water-gas shift activity of alkali-promoted platinum catalysts stabilized on carbon supports. J Am Chem Soc 136:3238-3245. https://doi.org/10.1021/ja412 3889

54. Lin J, Wang A, Qiao B, Liu X, Yang X, Wang X, Liang J, Li J, Liu J, Zhang T (2013) Remarkable performance of Ir $1 / \mathrm{FeOx}$ single-atom catalyst in water gas shift reaction. J Am Chem Soc 135:15314-15317. https://doi.org/10.1021/ja408574m

55. Yuan Z-Y, Idakiev V, Vantomme A, Tabakova T, Ren T-Z, Su B-L (2008) Mesoporous and nanostructured $\mathrm{CeO}_{2}$ as supports of nano-sized gold catalysts for low-temperature water-gas shift reaction. Catal Today 131:203-210. https://doi.org/10.1016/J. CATTOD.2007.10.050

56. Shekhar M, Wang J, Lee W-S, Williams WD, Kim SM, Stach EA, Miller JT, Delgass WN, Ribeiro FH (2012) Size and support effects for the water-gas shift catalysis over gold nanoparticles supported on model $\mathrm{Al}_{2} \mathrm{O}_{3}$ and $\mathrm{TiO}_{2}$. J Am Chem Soc 134:47004708. https://doi.org/10.1021/ja210083d

57. Yang HG, Sun CH, Qiao SZ, Zou J, Liu G, Smith SC, Cheng $\mathrm{HM}, \mathrm{Lu}$ GQ (2008) Anatase $\mathrm{TiO}_{2}$ single crystals with a large percentage of reactive facets. Nature 453:638-641. https://doi. org/10.1038/nature06964

58. Tian N, Zhou Z-Y, Sun S-G, Ding Y, Wang ZL (2007) Synthesis of tetrahexahedral platinum nanocrystals with high-index facets and high electro-oxidation activity. Science 316:732. https://doi. org/10.1126/science. 1140484 
59. Spencer ND, Schoonmaker RC, Somorjai GA (1981) Structure sensitivity in the iron single-crystal catalysed synthesis of ammonia. Nature 294:643-644. https://doi.org/10.1038/294643a0

60. Bratlie KM, Lee H, Komvopoulos K, Yang P, Somorjai GA (2007) Platinum nanoparticle shape effects on benzene hydrogenation selectivity. Nano Lett 7:3097-3101. https://doi. org/10.1021/n10716000

61. Zhang B, Wang D, Hou Y, Yang S, Yang XH, Zhong JH, Liu J, Wang HF, Hu P, Zhao HJ, Yang HG (2013) Facet-dependent catalytic activity of platinum nanocrystals for triiodide reduction in dye-sensitized solar cells. Sci Rep 3:1836. https://doi. org/10.1038/srep01836

62. Perez J, Gonzalez ER, Villullas HM (1998) Hydrogen evolution reaction on gold single-crystal electrodes in acid solutions. J Phys Chem B 102:10931-10935. https://doi.org/10.1021/jp983 1987

63. Chiu C-Y, Chung P-J, Lao K-U, Liao C-W, Huang MH (2012) Facet-dependent catalytic activity of gold nanocubes, octahedra, and rhombic dodecahedra toward 4-nitroaniline reduction. J Phys Chem C 116:23757-23763. https://doi.org/10.1021/jp307768h

64. Zhang J, Feng C, Deng Y, Liu L, Wu Y, Shen B, Zhong C, Hu W (2014) Shape-controlled synthesis of palladium single-crystalline nanoparticles: the effect of $\mathrm{HCl}$ oxidative etching and facetdependent catalytic properties. Chem Mater 26:1213-1218. https ://doi.org/10.1021/cm403591g

65. Shen Y, Chen P, Xiao D, Chen C, Zhu M, Li T, Ma W, Liu $\mathrm{M}$ (2015) Spherical and sheetlike $\mathrm{Ag} / \mathrm{AgCl}$ nanostructures: interesting photocatalysts with unusual facet-dependent yet substrate-sensitive reactivity. Langmuir 31:602-610. https://doi. org/10.1021/la504328j

66. Diebold U (2003) The surface science of titanium dioxide. Surf Sci Rep 48:53-229. https://doi.org/10.1016/S0167 -5729(02)00100-0

67. Bi Y, Ouyang S, Umezawa N, Cao J, Ye J (2011) Facet effect of single-crystalline $\mathrm{Ag}_{3} \mathrm{PO}_{4}$ sub-microcrystals on photocatalytic properties. J Am Chem Soc 133:6490-6492. https://doi. org/10.1021/ja2002132

68. $\mathrm{Hu} \mathrm{L}$, Peng Q, Li Y (2008) Selective synthesis of $\mathrm{Co}_{3} \mathrm{O}_{4}$ nanocrystal with different shape and crystal plane effect on catalytic property for methane combustion. J Am Chem Soc 130:16136-16137. https://doi.org/10.1021/ja806400e

69. Wang R, He H, Liu L-C, Dai H-X, Zhao Z (2012) Shape-dependent catalytic activity of palladium nanocrystals for the oxidation of carbon monoxide. Catal Sci Technol 2:575-580. https://doi. org/10.1039/C2CY00417H

70. Mishra AK, Pradhan D (2016) Morphology controlled solutionbased synthesis of $\mathrm{Cu}_{2} \mathrm{O}$ crystals for the facets-dependent catalytic reduction of highly toxic aqueous $\mathrm{Cr}(\mathrm{VI})$. Cryst Growth Des 16:3688-3698. https://doi.org/10.1021/acs.cgd.6b00186

71. Pal J, Mondal C, Sasmal AK, Ganguly M, Negishi Y, Pal T (2014) Account of nitroarene reduction with size- and facet-controlled $\mathrm{CuO}-\mathrm{MnO}_{2}$ nanocomposites. ACS Appl Mater Interfaces 6:9173-9184. https://doi.org/10.1021/am502866t

72. Ming T, Feng W, Tang Q, Wang F, Sun L, Wang J, Yan C (2009) Growth of tetrahexahedral gold nanocrystals with high-index facets. J Am Chem Soc 131:16350-16351. https://doi.org/10.1021/ ja907549n

73. Han X, Han X, Sun L, Gao S, Li L, Kuang Q, Xie Z, Wang C (2015) Synthesis of trapezohedral indium oxide nanoparticles with high-index 211 facets and high gas sensing activity. Chem Commun 51:9612-9615. https://doi.org/10.1039/C5CC02029H

74. Rehman S, Yang W, Liu F, Hong Y, Wang T, Hou Y (2015) Facile synthesis of anisotropic single crystalline $\alpha-\mathrm{Fe}_{2} \mathrm{O}_{3}$ nanoplates and their facet-dependent catalytic performance. Inorg Chem Front 2:576-583. https://doi.org/10.1039/C5QI00042D
75. Zhou K, Wang X, Sun X, Peng Q, Li Y (2005) Enhanced catalytic activity of ceria nanorods from well-defined reactive crystal planes. J Catal 229:206-212. https://doi.org/10.1016/J. JCAT.2004.11.004

76. Zhang L, Chen D, Jiang Z, Zhang J, Xie S, Kuang Q, Xie Z, Zheng L (2012) Facile syntheses and enhanced electrocatalytic activities of Pt nanocrystals with hkk high-index surfaces. Nano Res 5:181-189. https://doi.org/10.1007/s12274-012-0198-1

77. Kuo C-H, Mosa IM, Thanneeru S, Sharma V, Zhang L, Biswas S, Aindow M, Pamir Alpay S, Rusling JF, Suib SL, He J (2015) Facet-dependent catalytic activity of $\mathrm{MnO}$ electrocatalysts for oxygen reduction and oxygen evolution reactions. Chem Commun 51:5951-5954. https://doi.org/10.1039/C5CC01152C

78. Chanda K, Rej S, Huang MH (2013) Facet-dependent catalytic activity of $\mathrm{Cu}_{2} \mathrm{O}$ nanocrystals in the one-pot synthesis of 1,2,3-triazoles by multicomponent click reactions. Chemistry A 19:16036-16043. https://doi.org/10.1002/chem.201302065

79. James TE, Hemmingson SL, Campbell CT (2015) Energy of supported metal catalysts: from single atoms to large metal nanoparticles. ACS Catal 5:5673-5678. https://doi.org/10.1021/acsCa tal5b01372

80. Kiss J, Kukovecz Á, Kónya Z (2019) Beyond nanoparticles: the role of sub-nanosized metal species in heterogeneous catalysis. Catal Lett 149:1441-1454. https://doi.org/10.1007/s10562-01902734-6

81. Boronat M, Leyva-Pérez A, Corma A (2014) Theoretical and experimental insights into the origin of the catalytic activity of subnanometric gold clusters: attempts to predict reactivity with clusters and nanoparticles of gold. Acc Chem Res 47:834-844. https://doi.org/10.1021/ar400068w

82. Thomas JM, Midgley PA (2010) The merits of static and dynamic high-resolution electron microscopy (HREM) for the study of solid catalysts. ChemCatChem 2:783-798. https://doi. org/10.1002/cctc.201000059

83. Kaden WE, Wu T, Kunkel WA, Anderson SL (2009) Electronic structure controls reactivity of size-selected Pd clusters adsorbed on $\mathrm{TiO}_{2}$ surfaces. Science 326:826-829. https://doi.org/10.1126/ science. 1180297

84. Zhu M, Aikens CM, Hollander FJ, Schatz GC, Jin R (2008) Correlating the crystal structure of a thiol-protected Au25 cluster and optical properties. J Am Chem Soc 130:5883-5885. https://doi. org/10.1021/ja801173r

85. Wu Z, Jiang D, Mann AKP, Mullins DR, Qiao Z-A, Allard LF, Zeng C, Jin R, Overbury SH (2014) Thiolate ligands as a double-edged sword for $\mathrm{CO}$ oxidation on $\mathrm{CeO}_{2}$ supported $\mathrm{Au}_{25}\left(\mathrm{SCH}_{2} \mathrm{CH}_{2} \mathrm{Ph}\right)_{18}$ nanoclusters. J Am Chem Soc 136:61116122. https://doi.org/10.1021/ja5018706

86. Li H, Li L, Li Y (2013) The electronic structure and geometric structure of nanoclusters as catalytic active sites. Nanotechnol Rev 2:515-528. https://doi.org/10.1515/ntrev-2012-0069

87. Häkkinen H, Abbet S, Sanchez A, Heiz U, Landman U (2003) Structural, electronic, and impurity-doping effects in nanoscale chemistry: supported gold nanoclusters. Angew Chem Int Ed 42:1297-1300. https://doi.org/10.1002/anie.200390334

88. Gruene P, Rayner DM, Redlich B, van der Meer AFG, Lyon JT, Meijer G, Fielicke A (2008) Structures of neutral Au7, Au19, and Au20 clusters in the gas phase. Science 321:674-676. https ://doi.org/10.1126/science.1161166

89. Tian Y, Tatsuma T (2005) Mechanisms and applications of plasmon-induced charge separation at $\mathrm{TiO}_{2}$ films loaded with gold nanoparticles. J Am Chem Soc 127:7632-7637. https://doi. org/10.1021/ja042192u

90. Lee J, Shim HS, Lee M, Song JK, Lee D (2011) Size-controlled electron transfer and photocatalytic activity of $\mathrm{ZnO}-\mathrm{Au}$ nanoparticle composites. J Phys Chem Lett 2:2840-2845. https://doi. org/10.1021/jz2013352 
91. Fu Q, Wagner T (2007) Interaction of nanostructured metal overlayers with oxide surfaces. Surf Sci Rep 62:431-498. https://doi. org/10.1016/J.SURFREP.2007.07.001

92. Chen M, Goodman DW (2006) Catalytically active gold: from nanoparticles to ultrathin films. Acc Chem Res 39:739-746. https ://doi.org/10.1021/ar040309d

93. Schmid G (2008) The relevance of shape and size of Au55 clusters. Chem Soc Rev 37:1909-1930. https://doi.org/10.1039/ B713631P

94. Al Qahtani HS, Kimoto K, Bennett T, Alvino JF, Andersson GG, Metha GF, Golovko VB, Sasaki T, Nakayama T (2016) Atomically resolved structure of ligand-protected $\mathrm{Au} 9$ clusters on $\mathrm{TiO}_{2}$ nanosheets using aberration-corrected STEM. J Chem Phys 144:114703. https://doi.org/10.1063/1.4943203

95. Shaikhutdinov S, Freund H-J (2012) Ultrathin oxide films on metal supports: structure-reactivity relations. Annu Rev Phys Chem 63:619-633. https://doi.org/10.1146/annurev-physchem032511-143737

96. Zheng N, Stucky GD (2006) A general synthetic strategy for oxide-supported metal nanoparticle catalysts. J Am Chem Soc 128:14278-14280. https://doi.org/10.1021/ja0659929

97. Nie X, Qian H, Ge Q, Xu H, Jin R (2012) CO oxidation catalyzed by oxide-supported Au25(SR)18 nanoclusters and identification of perimeter sites as active centers. ACS Nano 6:6014-6022. https://doi.org/10.1021/nn301019f

98. Nie X, Zeng C, Ma X, Qian H, Ge Q, Xu H, Jin R (2013) $\mathrm{CeO}_{2}$-supported $\mathrm{Au}_{38}(\mathrm{SR})_{24}$ nanocluster catalysts for $\mathrm{CO}$ oxidation: a comparison of ligand-on and -off catalysts. Nanoscale 5:5912-5918. https://doi.org/10.1039/C3NR00970J

99. Gaur S, Miller JT, Stellwagen D, Sanampudi A, Kumar CSSR, Spivey JJ (2012) Synthesis, characterization, and testing of supported Au catalysts prepared from atomically-tailored $\mathrm{Au}_{38}\left(\mathrm{SC}_{12} \mathrm{H}_{25}\right)_{24}$ clusters. Phys Chem Chem Phys 14:1627-1634. https://doi.org/10.1039/C1CP22438G

100. Rosi NL, Giljohann DA, Thaxton CS, Lytton-Jean AKR, Han MS, Mirkin CA (2006) Oligonucleotide-modified gold nanoparticles for intracellular gene regulation. Science 312:1027. https ://doi.org/10.1126/science.1125559

101. Wohltjen H, Snow AW (1998) Colloidal metal-insulator-metal ensemble chemiresistor sensor. Anal Chem 70:2856-2859. https ://doi.org/10.1021/ac9713464

102. Heaven MW, Dass A, White PS, Holt KM, Murray RW (2008) Crystal structure of the gold nanoparticle $\left[\mathrm{N}\left(\mathrm{C}_{8} \mathrm{H}_{17}\right)_{4}\right]$ $\left[\mathrm{Au}_{25}\left(\mathrm{SCH}_{2} \mathrm{CH}_{2} \mathrm{Ph}\right)_{18}\right]$. J Am Chem Soc 130:3754-3755. https ://doi.org/10.1021/ja800561b

103. Sicot M, Leicht P, Zusan A, Bouvron S, Zander O, Weser M, Dedkov YS, Horn K, Fonin M (2012) Size-selected epitaxial nanoislands underneath graphene moiré on Rh (111). ACS Nano 6:151-158. https://doi.org/10.1021/nn203169j

104. Gotterbarm K, Späth F, Bauer U, Bronnbauer C, Steinrück H-P, Papp C (2015) Reactivity of graphene-supported Pt nanocluster arrays. ACS Catal 5:2397-2403. https://doi.org/10.1021/acsCa tal5b00245

105. Patterson MC, Habenicht BF, Kurtz RL, Liu L, Xu Y, Sprunger PT (2014) Formation and stability of dense arrays of Au nanoclusters on hexagonal boron nitride/Rh (111). Phys Rev B 89:205423. https://doi.org/10.1103/PhysRevB.89.205423

106. Gubó R, Vári G, Kiss J, Farkas AP, Palotás K, Óvári L, Berkó A, Kónya Z (2018) Tailoring the hexagonal boron nitride nanomesh on Rh (111) with gold. Phys Chem Chem Phys 20:15473-15485. https://doi.org/10.1039/C8CP00790J

107. Koch HP, Laskowski R, Blaha P, Schwarz K (2012) Adsorption of small gold clusters on the $\mathrm{h}-\mathrm{BN} / \mathrm{Rh}(111)$ nanomesh. Phys Rev B 86:155404. https://doi.org/10.1103/PhysRevB.86.155404

108. Farkas AP, Szitás Á, Vári G, Gubó R, Óvári L, Berkó A, Kiss J, Kónya Z (2018) Effect of gold on the adsorption properties of acetaldehyde on clean and h-BN covered Rh (111) surface. Top Catal 61:1247-1256. https://doi.org/10.1007/s11244-018-0979-1

109. Gottfried JM (2015) Surface chemistry of porphyrins and phthalocyanines. Surf Sci Rep 70:259-379. https://doi.org/10.1016/J. SURFREP.2015.04.001

110. Wang A, Li J, Zhang T (2018) Heterogeneous single-atom catalysis. Nat Rev Chem 2:65-81. https://doi.org/10.1038/s4157 0-018-0010-1

111. Bliem R, Pavelec J, Gamba O, McDermott E, Wang Z, Gerhold S, Wagner M, Osiecki J, Schulte K, Schmid M, Blaha P, Diebold U, Parkinson GS (2015) Adsorption and incorporation of transition metals at the magnetite $\mathrm{Fe}_{3} \mathrm{O}_{4}$ (001) surface. Phys Rev B 92:1-9. https://doi.org/10.1103/PhysRevB.92.075440

112. Gu XK, Qiao B, Huang CQ, Ding WC, Sun K, Zhan E, Zhang T, Liu J, Li WX (2014) Supported single Pt1/Au1 atoms for methanol steam reforming. ACS Catal 4:3886-3890. https:// doi.org/10.1021/cs500740u

113. Chen LN, Hou KP, Liu YS, Qi ZY, Zheng Q, Lu YH, Chen JY, Chen JL, Pao CW, Wang SB, Bin Li Y, Xie SH, Liu FD, Prendergast D, Klebanoff LE, Stavila V, Allendorf MD, Guo J, Zheng LS, Su J, Somorjai GA (2019) Efficient hydrogen production from methanol using a single-site $\mathrm{Pt} 1 / \mathrm{CeO}_{2}$ catalyst. J Am Chem Soc 141:17995-17999. https://doi.org/10.1021/ jacs.9b09431

114. Hegde MS, Madras G, Patil KC (2009) Noble metal ionic catalysts. Acc Chem Res 42:704-712. https://doi.org/10.1021/ar800 209s

115. Roy S, Hegde MS, Madras G (2009) Catalysis for NOx abatement. Appl Energy 86:2283-2297. https://doi.org/10.1016/j. apenergy.2009.03.022

116. Kibis LS, Kardash TY, Derevyannikova EA, Stonkus OA, Slavinskaya EM, Svetlichnyi VA, Boronin AI (2017) Redox and catalytic properties of $\mathrm{RhxCe} 1-\mathrm{xO} 2-\delta$ solid solution. J Phys Chem C 121:26925-26938. https://doi.org/10.1021/acs.jpcc.7b09983

117. Kibis LS, Svintsitskiy DA, Derevyannikova EA, Kardash TY, Slavinskaya EM, Stonkus OA, Svetlichnyi VA, Boronin AI (2019) From highly dispersed $\mathrm{Rh}^{3+}$ to nanoclusters and nanoparticles: probing the low-temperature $\mathrm{NO}+\mathrm{CO}$ activity of Rhdoped $\mathrm{CeO}_{2}$ catalysts. Appl Surf Sci 493:1055-1066. https://doi. org/10.1016/j.apsusc.2019.07.043

118. Bavykin DV, Walsh FC (2009) Titanate and titania nanotubes. R Soc Chem. https://doi.org/10.1039/9781849730778

119. Kasuga T, Hiramatsu M, Hoson A, Sekino T, Niihara K (1998) Formation of titanium oxide nanotube. Langmuir 14:3160-3163. https://doi.org/10.1021/la9713816

120. Kukovecz Á, Kordás K, Kiss J, Kónya Z (2016) Atomic scale characterization and surface chemistry of metal modified titanate nanotubes and nanowires. Surf Sci Rep 71:473-546. https://doi. org/10.1016/J.SURFREP.2016.06.001

121. Sun X, Li Y (2003) Synthesis and characterization of ionexchangeable titanate nanotubes. Chemistry A 9:2229-2238. https://doi.org/10.1002/chem.200204394

122. Pusztai P, Puskás R, Varga E, Erdőhelyi A, Kukovecz Á, Kónya Z, Kiss J (2014) Influence of gold additives on the stability and phase transformation of titanate nanostructures. Phys Chem Chem Phys 16:26786-26797. https://doi.org/10.1039/C4CP0 4084H

123. László B, Baán K, Varga E, Oszkó A, Erdőhelyi A, Kónya Z, Kiss J (2016) Photo-induced reactions in the $\mathrm{CO}_{2}$-methane system on titanate nanotubes modified with $\mathrm{Au}$ and $\mathrm{Rh}$ nanoparticles. Appl Catal B 199:473-484. https://doi.org/10.1016/J. APCATB.2016.06.057

124. Kukovecz Á, Pótári G, Oszkó A, Kónya Z, Erdőhelyi A, Kiss J (2011) Probing the interaction of $\mathrm{Au}, \mathrm{Rh}$ and bimetallic $\mathrm{Au}-\mathrm{Rh}$ clusters with the $\mathrm{TiO}_{2}$ nanowire and nanotube support. Surf Sci 605:1048-1055. https://doi.org/10.1016/J.SUSC.2011.03.003 
125. László B, Baán K, Oszkó A, Erdőhelyi A, Kiss J, Kónya Z (2018) Hydrogen evolution in the photocatalytic reaction between methane and water in the presence of $\mathrm{CO}_{2}$ on titanate and titania supported Rh and Au catalysts. Top Catal 61:875-888. https://doi. org/10.1007/s11244-018-0936-Z

126. Bonzel HP, Ku R (1972) Mechanisms of the catalytic carbon monoxide oxidation on Pt (110). Surf Sci 33:91-106. https://doi. org/10.1016/0039-6028(72)90101-X

127. Comrie CM, Weinberg WH, Lambert RM (1976) The adsorption of nitric oxide on $\mathrm{Pt}(111)$ and $\mathrm{Pt}(110)$ surfaces. Surf Sci 57:619-631. https://doi.org/10.1016/0039-6028(76)90351-4

128. Solymosi F, Kiss J (1981) Adsorption and surface dissociation of HNCO on Pt(110) surfaces: LEED, AES, ELS and TDS studies. Surf Sci 108:641-659. https://doi.org/10.1016/00396028(81)90570-7

129. Hagen DI, Nieuwenhuys BE, Rovida G, Somorjai GA (1976) Low-energy electron diffraction, Auger electron spectroscopy, and thermal desorption studies of chemisorbed $\mathrm{CO}$ and $\mathrm{O}_{2}$ on the $(111)$ and stepped [6(111) $\times(100)]$ iridium surfaces. Surf Sci 57:632-650. https://doi.org/10.1016/0039-6028(76)90352-6

130. Zasada I, Van Hove MA (2000) Refinement of the $\mathrm{Pt}(111)+\mathrm{c}(4 \times 2)-2 \mathrm{CO}$ structure using automated tensor LEED. Surf Rev Lett 07:15-19. https://doi.org/10.1142/S0218625X0 000004X

131. Imbihl R, Ertl G (1995) oscillatory kinetics in heterogeneous catalysis. Chem Rev 95:697-733. https://doi.org/10.1021/cr000 $35 \mathrm{a} 012$

132. Liu X, Chen T, Song P, Zhang Y, Xu W (2018) Single-molecule nanocatalysis of Pt nanoparticles. J Phys Chem C 122:17461752. https://doi.org/10.1021/acs.jpcc.7b11630

133. Majzik Z, Balázs N, Berkó A (2012) Thermally activated recon-

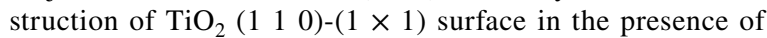
potassium: an STM study. Catal Today 181:89-94. https://doi. org/10.1016/J.CATTOD.2011.06.018

134. Bäumer M, Freund H-J (1999) Metal deposits on well-ordered oxide films. Prog Surf Sci 61:127-198. https://doi.org/10.1016/ S0079-6816(99)00012-X

135. Campbell CT (1997) Ultrathin metal films and particles on oxide surfaces: structural, electronic and chemisorptive properties. Surf Sci Rep 27:1-111. https://doi.org/10.1016/S0167-5729(96)00011 $-8$

136. Gunter PLJ, Niemantsverdriet JW, Ribeiro FH, Somorjai GA (1997) Surface science approach to modeling supported catalysts. Catal Rev 39:77-168. https://doi.org/10.1080/016149497080064 69

137. Solymosi F, Pasztor M (1985) An infrared study of the influence of carbon monoxide chemisorption on the topology of supported rhodium. J Phys Chem 89:4789-4793. https://doi.org/10.1021/ j100268a026

138. Buchanan DA, Hernandez ME, Solymosi F, White JM (1990) CO-induced structural changes of $\mathrm{Rh}$ on $\mathrm{TiO}_{2}$ Support. J Catal 125:456-466. https://doi.org/10.1016/0021-9517(90)90318-E

139. Berkó A, Solymosi F (2000) Effects of different gases on the morphology of Ir nanoparticles supported on the $\mathrm{TiO}_{2}(110)-(1 \times 2)$ surface. J Phys Chem B 104:10215-10221. https://doi. org/10.1021/jp002065u

140. Berkó A, Szökő J, Solymosi F (2004) Effect of CO on the morphology of Pt nanoparticles supported on $\mathrm{TiO}_{2}\left(\begin{array}{lll}1 & 1 & 0\end{array}\right)-\left(\begin{array}{l}1 \\ 1\end{array}\right.$ $\times \mathrm{n})$. Surf Sci 566-568:337-342. https://doi.org/10.1016/J. SUSC.2004.05.065

141. Kiss J, Óvári L, Oszkó A, Pótári G, Tóth M, Baán K, Erdóhelyi A (2012) Structure and reactivity of $\mathrm{Au}-\mathrm{Rh}$ bimetallic clusters on titanate nanowires, nanotubes and $\mathrm{TiO}_{2}\left(\begin{array}{lll}1 & 1 & 0\end{array}\right)$. Catal Today 181:163-170. https://doi.org/10.1016/J.CATTOD.2011.06.002

142. Tenney SA, Ratliff JS, Roberts CC, He W, Ammal SC, Heyden A, Chen DA (2010) Adsorbate-induced changes in the surface composition of bimetallic clusters: $\mathrm{Pt}-\mathrm{Au}$ on $\mathrm{TiO}_{2}$ (110). J Phys Chem C 114:21652-21663. https://doi.org/10.1021/jp108939h

143. Gao F, Wang Y, Goodman DW (2010) Reaction kinetics and polarization-modulation infrared reflection absorption spectroscopy (PM-IRAS) investigation of CO oxidation over supported Pd-Au alloy catalysts. J Phys Chem C 114:4036-4043. https:// doi.org/10.1021/jp910896k

144. Solymosi F (1985) Comments on electronic effects in strong metal-support interactions on titania-deposited metal catalysts. J Catal 94:581-585. https://doi.org/10.1016/0021-9517(85)90226 -X

145. Tauster SJ, Fung SC, Garten RL (1978) Strong metal-support interactions. Group 8 noble metals supported on titanium dioxide. J Am Chem Soc 100:170-175. https://doi.org/10.1021/ ja00469a029

146. Lin L, Yao S, Liu Z, Zhang F, Li N, Vovchok D, MartínezArias A, Castañeda R, Lin J, Senanayake SD, Su D, Ma D, Rodriguez JA (2018) In situ characterization of $\mathrm{Cu} / \mathrm{CeO}_{2}$ nanocatalysts for $\mathrm{CO}_{2}$ hydrogenation: morphological effects of nanostructured ceria on the catalytic activity. J Phys Chem C 122:12934-12943. https://doi.org/10.1021/acs.jpcc.8b03596

147. Wang W-W, Yu W-Z, Du P-P, Xu H, Jin Z, Si R, Ma C, Shi S, Jia C-J, Yan C-H (2017) Crystal plane effect of ceria on supported copper oxide cluster catalyst for $\mathrm{CO}$ oxidation: importance of metal-support interaction. ACS Catal 7:1313-1329. https://doi.org/10.1021/acsCatal6b03234

148. Zabilskiy M, Djinović P, Tchernychova E, Tkachenko OP, Kustov LM, Pintar A (2015) Nanoshaped $\mathrm{CuO} / \mathrm{CeO}_{2}$ materials: effect of the exposed ceria surfaces on catalytic activity in $\mathrm{N}_{2} \mathrm{O}$ decomposition reaction. ACS Catal 5:5357-5365. https://doi. org/10.1021/acsCatal5b01044

149. Ouyang B, Tan W, Liu B (2017) Morphology effect of nanostructure ceria on the $\mathrm{Cu} / \mathrm{CeO}_{2}$ catalysts for synthesis of methanol from $\mathrm{CO}_{2}$ hydrogenation. Catal Commun 95:36-39. https ://doi.org/10.1016/j.catcom.2017.03.005

150. Si R, Flytzani-Stephanopoulos M (2008) Shape and crystalplane effects of nanoscale ceria on the activity of $\mathrm{Au}-\mathrm{CeO}_{2}$ catalysts for the water-gas shift reaction. Angew Chemie Int Ed 47:2884-2887. https://doi.org/10.1002/anie.200705828

151. da Silva AM, de Souza KR, Mattos LV, Jacobs G, Davis BH, Noronha FB (2011) The effect of support reducibility on the stability of $\mathrm{Co} / \mathrm{CeO}_{2}$ for the oxidative steam reforming of ethanol. Catal Today 164:234-239. https://doi.org/10.1016/j.catto d.2010.10.033

152. Martono E, Vohs JM (2011) Active sites for the reaction of ethanol to acetaldehyde on Co/YSZ(100) model steam reforming catalysts. ACS Catal 1:1414-1420. https://doi.org/10.1021/ cs200404h

153. Overbury SH, Mullins DR, Kundakovic L (2001) Enhancement of dissociation by metal-support interaction: reaction of $\mathrm{NO}$ on Rh supported by ceria films of controlled oxidation state. Surf Sci 470:243-254. https://doi.org/10.1016/S0039 -6028(00)00864-5

154. Varga E, Pusztai P, Oszkó A, Baán K, Erdőhelyi A, Kónya Z, Kiss J (2016) Stability and temperature-induced agglomeration of $\mathrm{Rh}$ nanoparticles supported by $\mathrm{CeO}_{2}$. Langmuir 32:27612770. https://doi.org/10.1021/acs.langmuir.5b04482

155. Cook KM, Poudyal S, Miller JT, Bartholomew CH, Hecker WC (2012) Reducibility of alumina-supported cobalt Fischer-Tropsch catalysts: effects of noble metal type, distribution, retention, chemical state, bonding, and influence on cobalt crystallite size. Appl Catal A 449:69-80. https://doi. org/10.1016/j.apcata.2012.09.032

156. Guo Y, Mei S, Yuan K, Wang D-J, Liu H-C, Yan C-H, Zhang Y-W (2018) Low-temperature $\mathrm{CO}_{2}$ methanation over $\mathrm{CeO}_{2}$-supported $\mathrm{Ru}$ single atoms, nanoclusters, and 
nanoparticles competitively tuned by strong metal-support interactions and H-spillover effect. ACS Catal 8:6203-6215. https://doi.org/10.1021/acsCatal7b04469

157. Qin Z-H, Lewandowski M, Sun Y-N, Shaikhutdinov S, Freund H-J (2008) Encapsulation of Pt nanoparticles as a result of strong metal-support interaction with $\mathrm{Fe}_{3} \mathrm{O}_{4}$ (111). J Phys Chem C 112:10209-10213. https://doi.org/10.1021/jp801756q

158. Shaikhutdinov S (2018) Strong metal-support interaction and reactivity of ultrathin oxide films. Catal Lett 148:2627-2635. https://doi.org/10.1007/s10562-018-2499-9

159. Majzik Z, Balázs N, Berkó A (2011) Ordered SMSI decoration layer on $\mathrm{Rh}$ nanoparticles grown on $\mathrm{TiO}_{2}$ (110) surface. J Phys Chem C 115:9535-9544. https://doi.org/10.1021/jp111319n

160. Óvári L, Kiss J (2006) Growth of Rh nanoclusters on $\mathrm{TiO}_{2}(11$ $0)$ : XPS and LEIS studies. Appl Surf Sci 252:8624-8629. https ://doi.org/10.1016/J.APSUSC.2005.11.081

161. Sinfelt JH (1983) Bimetallic catalysts, exxon monograph series 7. Wiley, New York

162. Sinfelt JH (1977) Catalysis by alloys and bimetallic clusters. Acc Chem Res 10:15-20. https://doi.org/10.1021/ar50109a00 3

163. Kitchin JR, Nørskov JK, Barteau MA, Chen JG (2004) Role of strain and ligand effects in the modification of the electronic and chemical properties of bimetallic surfaces. Phys Rev Lett 93:156801. https://doi.org/10.1103/PhysRevLett93.156801

164. Gilroy KD, Ruditskiy A, Peng H-C, Qin D, Xia Y (2016) Bimetallic nanocrystals: syntheses, properties, and applications. Chem Rev 116:10414-10472. https://doi.org/10.1021/acs.chemr ev.6b00211

165. Sankar M, Dimitratos N, Miedziak PJ, Wells PP, Kiely CJ, Hutchings GJ (2012) Designing bimetallic catalysts for a green and sustainable future. Chem Soc Rev 41:8099-8139. https://doi. org $/ 10.1039 / \mathrm{C} 2 \mathrm{CS} 35296 \mathrm{~F}$

166. De S, Zhang J, Luque R, Yan N (2016) Ni-based bimetallic heterogeneous catalysts for energy and environmental applications. Energy Environ Sci 9:3314-3347. https://doi.org/10.1039/ C6EE02002J

167. Gu J, Zhang Y-W, Tao F (2012) Shape control of bimetallic nanocatalysts through well-designed colloidal chemistry approaches. Chem Soc Rev 41:8050-8065. https://doi.org/10.1039/C2CS3 $5184 \mathrm{~F}$

168. Karim A, Conant T, Datye A (2006) The role of PdZn alloy formation and particle size on the selectivity for steam reforming of methanol. J Catal 243:420-427. https://doi.org/10.1016/J. JCAT.2006.07.024

169. Zhang H, Jin M, Liu H, Wang J, Kim MJ, Yang D, Xie Z, Liu J, Xia Y (2011) Facile synthesis of Pd-Pt alloy nanocages and their enhanced performance for preferential oxidation of $\mathrm{CO}$ in excess hydrogen. ACS Nano 5:8212-8222. https://doi.org/10.1021/ nn202896q

170. Halevi B, Peterson EJ, DeLaRiva A, Jeroro E, Lebarbier VM, Wang Y, Vohs JM, Kiefer B, Kunkes E, Havecker M, Behrens M, Schlögl R, Datye AK (2010) Aerosol-derived bimetallic alloy powders: bridging the gap. J Phys Chem C 114:17181-17190. https://doi.org/10.1021/jp103967x

171. Tao F, Dag S, Wang L-W, Liu Z, Butcher DR, Bluhm H, Salmeron M, Somorjai GA (2010) Break-up of stepped platinum catalyst surfaces by high CO coverage. Science 327:850. https://doi. org/10.1126/science.1182122

172. Longwitz SR, Schnadt J, Vestergaard EK, Vang RT, Stensgaard I, Brune H, Besenbacher F (2004) High-coverage structures of carbon monoxide adsorbed on $\mathrm{Pt}(111)$ studied by high-pressure scanning tunneling microscopy. J Phys Chem B 108:1449714502. https://doi.org/10.1021/jp0492218

173. Zhang L, Karim AM, Engelhard MH, Wei Z, King DL, Wang $\mathrm{Y}$ (2012) Correlation of Pt-Re surface properties with reaction pathways for the aqueous-phase reforming of glycerol. J Catal 287:37-43. https://doi.org/10.1016/J.JCAT.2011.11.015

174. Schubert MM, Kahlich MJ, Feldmeyer G, Hüttner M, Hackenberg S, Gasteiger HA, Behm RJ (2001) Bimetallic PtSn catalyst for selective $\mathrm{CO}$ oxidation in $\mathrm{H}_{2}$-rich gases at low temperatures. Phys Chem Chem Phys 3:1123-1131. https://doi.org/10.1039/ B008062O

175. Li D, Nakagawa Y, Tomishige K (2011) Methane reforming to synthesis gas over Ni catalysts modified with noble metals. Appl Catal A 408:1-24. https://doi.org/10.1016/J.APCAT A.2011.09.018

176. Li B, Kado S, Mukainakano Y, Miyazawa T, Miyao T, Naito S, Okumura K, Kunimori K, Tomishige K (2007) Surface modification of Ni catalysts with trace Pt for oxidative steam reforming of methane. J Catal 245:144-155. https://doi.org/10.1016/J. JCAT.2006.10.004

177. Nilekar AU, Alayoglu S, Eichhorn B, Mavrikakis M (2010) Preferential CO oxidation in hydrogen: reactivity of core-shell nanoparticles. J Am Chem Soc 132:7418-7428. https://doi. org/10.1021/ja101108w

178. Li H, Yu X, Tu S-T, Yan J, Wang Z (2010) Catalytic performance and characterization of $\mathrm{Al}_{2} \mathrm{O}_{3}$-supported $\mathrm{Pt}-\mathrm{Co}$ catalyst coatings for preferential $\mathrm{CO}$ oxidation in a micro-reactor. Appl Catal A 387:215-223. https://doi.org/10.1016/J.APCATA.2010.08.030

179. Alexeev OS, Gates BC (2003) Supported bimetallic cluster catalysts. Ind Eng Chem Res 42:1571-1587. https://doi.org/10.1021/ ie020351h

180. Wang X, Li N, Pfefferle LD, Haller GL (2009) Pt-Co bimetallic catalyst supported on single walled carbon nanotube: XAS and aqueous phase reforming activity studies. Catal Today 146:160 165. https://doi.org/10.1016/J.CATTOD.2009.02.010

181. Ferrandon M, Kropf AJ, Krause T (2010) Bimetallic Ni-Rh catalysts with low amounts of $\mathrm{Rh}$ for the steam and autothermal reforming of n-butane for fuel cell applications. Appl Catal A 379:121-128. https://doi.org/10.1016/J.APCATA.2010.03.013

182. Frenkel AI (2012) Applications of extended X-ray absorption fine-structure spectroscopy to studies of bimetallic nanoparticle catalysts. Chem Soc Rev 41:8163-8178. https://doi.org/10.1039/ C2CS35174A

183. Starr DE, Liu Z, Hävecker M, Knop-Gericke A, Bluhm H (2013) Investigation of solid/vapor interfaces using ambient pressure X-ray photoelectron spectroscopy. Chem Soc Rev 42:5833-5857. https://doi.org/10.1039/C3CS60057B

184. Rodriguez JA, Hanson JC, Chupas PJ (2013) In-situ characterization of heterogeneous catalysts. Wiley, Hoboken. https://doi. org/10.1002/9781118355923

185. Dai S, You Y, Zhang S, Cai W, Xu M, Xie L, Wu R, Graham GW, Pan X (2017) In situ atomic-scale observation of oxygendriven core-shell formation in Pt 3 Co nanoparticles. Nat Commun 8:204. https://doi.org/10.1038/s41467-017-00161-y

186. Kitchin J, Reuter K, Scheffler M (2008) Alloy surface segregation in reactive environments: first-principles atomistic thermodynamics study of $\mathrm{Ag} 3 \mathrm{Pd}(111)$ in oxygen atmospheres. Phys Rev B. https://doi.org/10.1103/PhysRevB.77.075437

187. Dai S, Hou Y, Onoue M, Zhang S, Gao W, Yan X, Graham GW, Wu R, Pan X (2017) Revealing surface elemental composition and dynamic processes involved in facet-dependent oxidation of Pt 3 Co nanoparticles via in situ transmission electron microscopy. Nano Lett 17:4683-4688. https://doi.org/10.1021/acs. nanoLett7b01325

188. Zhan W, Wang J, Wang H, Zhang J, Liu X, Zhang P, Chi M, Guo Y, Guo Y, Lu G, Sun S, Dai S, Zhu H (2017) Crystal structural effect of $\mathrm{AuCu}$ alloy nanoparticles on catalytic $\mathrm{CO}$ oxidation. J Am Chem Soc 139:8846-8854. https://doi.org/10.1021/ jacs.7b01784 
189. Liu X, Wang A, Li L, Zhang T, Mou C-Y, Lee J-F (2011) Structural changes of $\mathrm{Au}-\mathrm{Cu}$ bimetallic catalysts in $\mathrm{CO}$ oxidation: in situ XRD, EPR, XANES, and FT-IR characterizations. J Catal 278:288-296. https://doi.org/10.1016/J.JCAT.2010.12.016

190. Escudero C, Salmeron M (2013) From solid-vacuum to solid-gas and solid-liquid interfaces: in situ studies of structure and dynamics under relevant conditions. Surf Sci. https://doi.org/10.1016/j. susc. 2012.08.007

191. Tao F, Salmeron M (2011) In situ studies of chemistry and structure of materials in reactive environments. Science 331:171. https ://doi.org/10.1126/science.1197461

192. Zheng H, Smith RK, Jun Y, Kisielowski C, Dahmen U, Alivisatos AP (2009) Observation of single colloidal platinum nanocrystal growth trajectories. Science 324:1309. https://doi.org/10.1126/ science. 1172104

193. Hansen PL, Wagner JB, Helveg S, Rostrup-Nielsen JR, Clausen BS, Topsøe H (2002) Atom-resolved imaging of dynamic shape changes in supported copper nanocrystals. Science 295:2053. https://doi.org/10.1126/science.1069325

194. Ketteler G, Ogletree DF, Bluhm H, Liu H, Hebenstreit ELD, Salmeron M (2005) In situ spectroscopic study of the oxidation and reduction of Pd (111). J Am Chem Soc 127:18269-18273. https://doi.org/10.1021/ja055754y

195. Vestergaard EK, Vang RT, Knudsen J, Pedersen TM, An T, Lægsgaard E, Stensgaard I, Hammer B, Besenbacher F (2005) Adsorbate-induced alloy phase separation: a direct view by high-pressure scanning tunneling microscopy. Phys Rev Lett 95:126101. https://doi.org/10.1103/PhysRevLett95.126101

196. de Smit E, Swart I, Creemer JF, Hoveling GH, Gilles MK, Tyliszczak T, Kooyman PJ, Zandbergen HW, Morin C, Weckhuysen BM, de Groot FMF (2008) Nanoscale chemical imaging of a working catalyst by scanning transmission X-ray microscopy. Nature 456:222-225. https://doi.org/10.1038/nature07516

197. Liu K, Wang A, Zhang W, Wang J, Huang Y, Shen J, Zhang T (2010) Quasi in situ 57Fe Mössbauer spectroscopic study: quantitative correlation between $\mathrm{Fe}^{2+}$ and $\mathrm{H}_{2}$ concentration for PROX over $\mathrm{Ir}-\mathrm{Fe} / \mathrm{SiO}_{2}$ catalyst. J Phys Chem C 114:8533-8541. https ://doi.org/10.1021/jp101697e

198. Crozier PA, Wang R, Sharma R (2008) In situ environmental TEM studies of dynamic changes in cerium-based oxides nanoparticles during redox processes. Ultramicroscopy 108:14321440. https://doi.org/10.1016/J.ULTRAMIC.2008.05.015
199. Wen C, Zhu Y, Ye Y, Zhang S, Cheng F, Liu Y, Wang P, Tao F (2012) Water-gas shift reaction on metal nanoclusters encapsulated in mesoporous ceria studied with ambient-pressure X-ray photoelectron spectroscopy. ACS Nano 6:9305-9313. https://doi. org/10.1021/nn303901q

200. Yoshida H, Kuwauchi Y, Jinschek JR, Sun K, Tanaka S, Kohyama M, Shimada S, Haruta M, Takeda S (2012) Visualizing gas molecules interacting with supported nanoparticulate catalysts at reaction conditions. Science 335:317. https://doi.org/10.1126/ science. 1213194

201. Tao F, Grass ME, Zhang Y, Butcher DR, Renzas JR, Liu Z, Chung JY, Mun BS, Salmeron M, Somorjai GA (2008) Reactiondriven restructuring of Rh-Pd and Pt-Pd core-shell nanoparticles. Science 322:932. https://doi.org/10.1126/science.1164170

202. Alayoglu S, Tao F, Altoe V, Specht C, Zhu Z, Aksoy F, Butcher DR, Renzas RJ, Liu Z, Somorjai GA (2011) Surface composition and catalytic evolution of AuxPd1-x $(\mathrm{x}=0.25,0.50$ and 0.75$)$ nanoparticles under $\mathrm{CO} / \mathrm{O}_{2}$ reaction in torr pressure regime and at $200^{\circ} \mathrm{C}$. Catal Lett 141:633-640. https://doi.org/10.1007/s1056 2-011-0565-7

203. Musselwhite N, Alayoglu S, Melaet G, Pushkarev VV, Lindeman AE, An K, Somorjai GA (2013) Isomerization of n-Hexane catalyzed by supported monodisperse PtRh bimetallic nanoparticles. Catal Lett 143:907-911. https://doi.org/10.1007/s1056 2-013-1068-5

204. Óvári L, Bugyi L, Majzik Z, Berkó A, Kiss J (2008) Surface structure and composition of $\mathrm{Au}-\mathrm{Rh}$ bimetallic nanoclusters on $\mathrm{TiO}_{2}$ (110): A LEIS and STM study. J Phys Chem C 112:1801118016. https://doi.org/10.1021/jp804348m

205. Óvári L, Berkó A, Balázs N, Majzik Z, Kiss J (2010) Formation of $\mathrm{Rh}-\mathrm{Au}$ core-shell nanoparticles on $\mathrm{TiO}_{2}(110)$ surface studied by STM and LEIS. Langmuir 26:2167-2175. https://doi. org/10.1021/la902674u

206. Berkó A, Gubó R, Óvári L, Kónya Z (2015) Rh and Au deposited on ultrathin $\mathrm{TiO} \sim 1.2$ film formed on $\mathrm{Rh}$ (111) facets and the effects of CO exposure. Surf Sci 641:300-304. https://doi. org/10.1016/J.SUSC.2015.02.016

Publisher's Note Springer Nature remains neutral with regard to jurisdictional claims in published maps and institutional affiliations. 